Portland State University

PDXScholar

$12-9-2020$

\title{
Relationships Between In-Situ Tests and Soil Cyclic Strength for Earthquake Hazard Characterization in the Pacific Northwest
}

Tanner Scott Bryantt

Portland State University

Follow this and additional works at: https://pdxscholar.library.pdx.edu/open_access_etds

Part of the Geotechnical Engineering Commons, and the Soil Science Commons Let us know how access to this document benefits you.

Recommended Citation

Bryantt, Tanner Scott, "Relationships Between In-Situ Tests and Soil Cyclic Strength for Earthquake Hazard Characterization in the Pacific Northwest" (2020). Dissertations and Theses. Paper 5629. https://doi.org/10.15760/etd.7501

This Thesis is brought to you for free and open access. It has been accepted for inclusion in Dissertations and Theses by an authorized administrator of PDXScholar. Please contact us if we can make this document more accessible: pdxscholar@pdx.edu. 
Relationships Between In-Situ Tests and Soil Cyclic Strength for Earthquake Hazard Characterization in the Pacific Northwest

by

Tanner Scott Bryantt

A thesis submitted in partial fulfillment of the requirements for the degree of

Master of Science

in

Civil and Environmental Engineering

Thesis Committee:

Diane Moug, Chair

Arash Khosravifar

Peter Dusicka

Portland State University

2020 


\begin{abstract}
Strong earthquake shaking is a natural hazard threat in the Pacific Northwest. Soil failure due to strong earthquake shaking - known as cyclic soil failure or liquefaction - is expected to cause large ground deformations and damage to roads, bridges, and other civil infrastructure. Cyclic soil strength (CRR) is often characterized with in-situ geotechnical tests including the cone penetration test (CPT). Relationships between CRR and in-situ test data are not well established for soils in the Pacific Northwest. Portland State University, in partnership with New Albion Geotechnical has compiled a database of cyclic lab tests for Pacific Northwest soils to characterize the behavior of these soils during a seismic event. This research presents investigation into relationships between CPT data and laboratory measurements of CRR. Preliminary findings suggest that relationships exist based on soil behavior type and plasticity indices. This research provides a basis to guide geotechnical engineering and geotechnical earthquake hazard characterization.
\end{abstract}


I'd like to dedicate this dissertation to my family, who have supported me greatly and without whose help I could not have wrote this. I'd like to thank Dr. Moug and Dr. Khosravifar for allowing me to take part in this exciting research and for their guidance throughout my studies. I'd also like to thank the many geotechnical consultants who assisted me in my studies and who have provided invaluable knowledge and resources relevant to this dissertation. 


\section{Contents \\ Abstract.}

Dedication

.ii

List of Figures.

\section{..v}

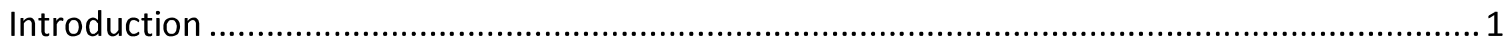

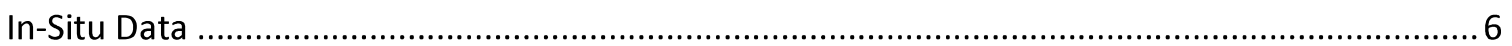

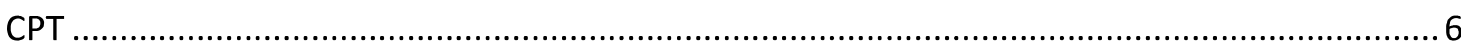

SPT

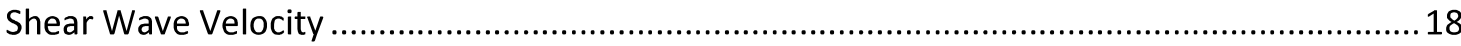

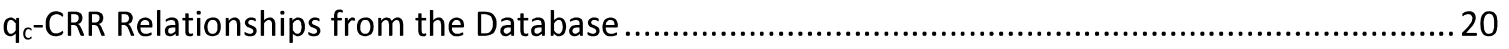

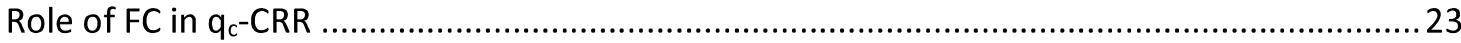

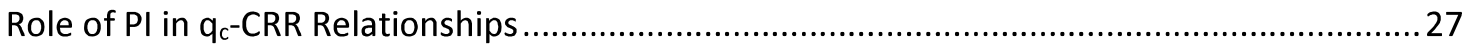

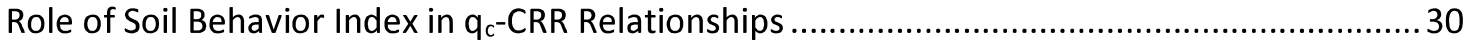

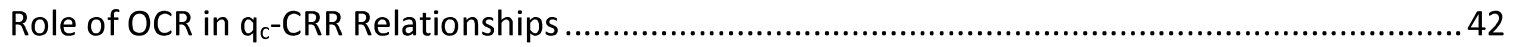

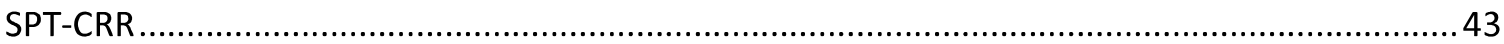

$\mathrm{V}_{\mathrm{s}}$-CRR

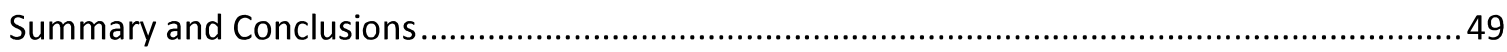

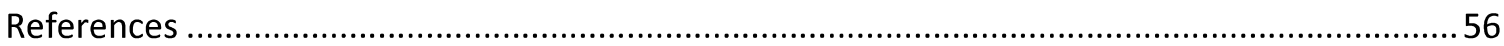


Appendix A Project Site Data Source Summary:

Appendix B: Summary In-Situ Parameters. 
List of Figures

Figure 1. CPT-3C profile from project $0-05$. The samples were taken from exploration

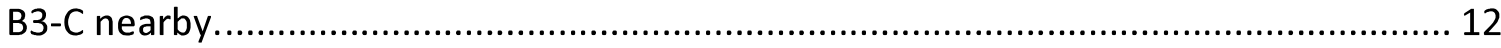

Figure 2. Database FC versus SBT Index from Idriss and Boulanger (2014). .................. 13 Figure 3. CPT data from Oregon and Washington analyzed in this research. Figure from

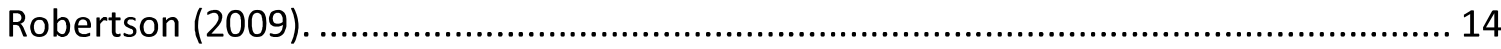

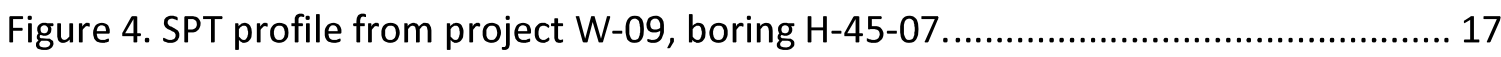

Figure 5.Boring log excerpt from project W-02 ....................................................... 19

Figure 6. Corrected $\mathrm{q}_{\mathrm{c}}$ data plotted against laboratory determined CRR normalized to a Magnitude 7.5 earthquake.

Figure 7.Normalized $\mathrm{q}_{\mathrm{c}}$ data plotted against CRR normalized to a Magnitude 7.5 earthquake.

Figure 8. Equivalent clean sand normalized $\mathrm{q}_{\mathrm{c}}$ data plotted against CRR normalized to a Magnitude 7.5 earthquake. 22

Figure 9. Deterministic triggering of sand-like behavior by FC from Idriss and Boulanger (2014). 23

Figure 10. Corrected $q_{c}$ data played against CRR and categorized by FC........................ 24

Figure 11. Normalized $\mathrm{q}_{\mathrm{c}}$ data plotted against CRR and categorized by FC. .................. 25 Figure 12. Equivalent clean sand normalized $q_{c}$ data categorized into sand-like behavior.

Figure 13.Corrected $\mathrm{q}_{\mathrm{c}}$ data plotted against-CRR data with PI and FC labels. 26

Figure 14. Normalized $\mathrm{q}_{\mathrm{c}}$ data plotted against CRR and categorized by PI and supplemented by FC. 29

Figure 15. Corrected $q_{c}$ data plotted against-CRR and categorized by Ic...................... 31

Figure 16. Soil behavior type indices chart from Robertson (2010)............................... 32

Figure 17. Corrected $\mathrm{q}_{\mathrm{c}}$ data plotted against CRR and categorized by Ic (2.05-2.60) and PI (0-7), with FC as a supplement. 33

Figure 18. Corrected $q_{c}$ data plotted against CRR and categorized by Ic (greater than 2.6) and PI (greater than 7) with FC as a supplement. 34 Figure 19. Corrected $q_{c}$ data plotted against CRR and categorized by lc (greater than 2.6)

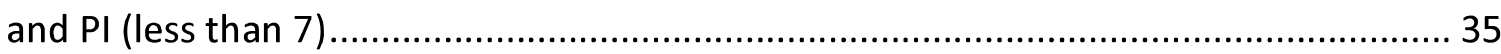

Figure 20. Normalized $q_{c}$ data plotted against CRR and categorized by Ic. ................... 36 Figure 21. Normalized $q_{c}$ data plotted against CRR and categorized by Ic (greater than 2.6), and PI (greater than 7).

Figure 22. Normalized $q_{c}$ data plotted against CRR and categorized by PI (greater than 7).Original figure data $q_{c}-C R R$ relationships for intermediate soils from Price et al. (2015)

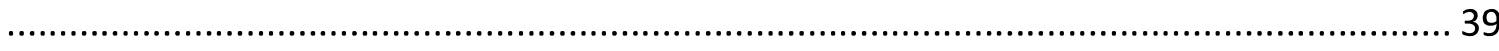
Figure 23. Normalized cone tip resistance data plotted against CRR and categorized by Ic (greater than 2.6) and PI (less than7). 40 
Figure 24. Equivalent clean sand normalized $\mathrm{q}_{\mathrm{c}}$ resistance data plotted against CRR and categorized by Ic and $\mathrm{PI}$.

Figure 25. Normalized cone tip resistance plotted against CRR categorized by OCR ..... 42

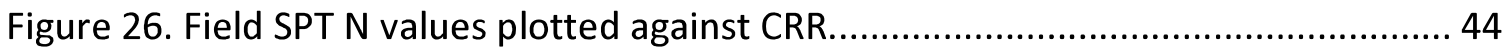

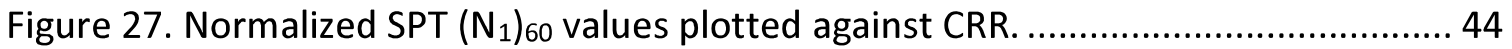

Figure 28. Equivalent clean sand normalized SPT $\left(\mathrm{N}_{1}\right)_{60 c s}$ data plotted against CRR. ..... 45

Figure 29. Shear Wave velocity, Vs, data plotted against CRR .................................. 47

Figure 30 . Normalized shear wave velocity, $\mathrm{V}_{s 1}$, data plotted against CRR. .................... 48

Figure 31. $\mathrm{q}_{\mathrm{c} 1 \mathrm{~N}}-\mathrm{CRR}$ relationships for silty soils in the pacific northwest. ...................... 53 
Introduction

Effective site investigation is essential to characterizing geotechnical earthquake hazards such as soil liquefaction susceptibility. Site investigation involves a combination of drilling and sampling, in-situ testing, and laboratory testing. The objectives of site investigation include characterizing soil design properties, soil types, site stratigraphy, or identify critical soil layers. The cone penetration test is a widely used in-situ test for soil characterization. The CPT has major advantages over traditional methods of field site investigation, such as drilling and sampling, because it is fast, repeatable, and economical. In addition, it provides near-continuous data and has a strong theoretical background (Robertson 2009).

An often-used application of the CPTu is to characterize earthquake geohazards. Specifically, earthquake induced liquefaction or soil softening. Many relationships between in-situ testing and cyclic strength have been developed via case histories where liquefaction was observed or was not observed during strong earthquake shaking. These case studies usually include in-situ measurements such as CPTu cone tip resistance, or SPT N blowcounts that relate the equivalent shear loading imparted by the earthquake shaking where liquefaction triggering did or did not occur. Most of these triggering relationships are developed for sandy soils, such as Idriss and Boulanger (2014). In the Pacific Northwest there is a presence of many silty soils. However, there are few case 
studies which examined liquefaction triggering or no triggering in silty soils, and therefore a case history-based relationship for silty soils is not available.

Some have researched liquefaction susceptibility of silts, such as Shuttle and Cunning (2007) and Karim and Alam (2014)Shuttle and Cunning (2007) analyzed the behavior of loose, under-consolidate or normally consolidated silt tailings during cone penetration and did not test for cyclic resistance in the laboratory. The silts observed in this research are normally and over-consolidated and likely not comparable to the behavior of the silt tailings observed by Shuttle and Cunning (2007) Karim and Alam (2014) analyzed the effect of non-plastic silt content on CRR, whereas in this research most silts were found to be plastic to some extent.

Liquefaction and cyclic softening have been confirmed to occur under strong earthquake loading (Bray and Sancio 2006), but these cases are relatively few compared to the number of liquefied sand case histories This lack of case histories is a limitation of seismic geohazard characterization in the Pacific Northwest.

To overcome discrepancies in case histories for silty soils, an attempt to characterize the cyclic behavior of these soils is underway via the database developed by New Albion Geotechnical, LLC and Portland State University. The database was developed from geotechnical engineering projects which included in-situ testing and cyclic sampling. The database includes 10 projects from Oregon, and 4 projects from Washington that included in-situ testing and that are the focus of this dissertation. Cyclic lab testing 
analyzed in this dissertation includes stress and strain-controlled direct simple shear tests (CDSS), and stress-controlled cyclic triaxial tests (CTX). In-situ testing includes cone penetration testing (CPT), standard penetration tests (SPT), and shear wave velocity measurements $\left(V_{s}\right)$.

The objective of this research is to perform a preliminary analysis of a relationship between in-situ test measurements with cyclic resistance ratio (CRR) of soils in the database. This preliminary analysis will include a suggestion of how to categorize the cyclic behavior of soils with in-situ data based on a suggested soil type. These suggested soil types included in this research are sand-like, clay-like, and transitional. Whether a soil falls into sand-like, clay-like, or transitional will be determined by in-situ qc data as well as laboratory data and discussed further in the following sections.

Generally, datapoints for the relationship are generated from project sites with (i) CRR values from soil that was sampled at a certain depth in the soil profile then laboratory tested with either CDSS or CTX, and (ii) in-situ test data from CPT, SPT, and/or that was evaluated to find values representative of the soil that was sampled and tested. The cyclic data was extracted by Professor Khosravifar of Portland State University and corrected for field conditions per Idriss and Boulanger (2008). The CPT parameters analyzed herein include corrected cone tip resistance $\left(q_{t}\right)$, normalized cone tip resistance $\left(q_{c 1 N}\right)$, and equivalent clean sand normalized cone tip resistance $\left(\mathrm{q}_{\mathrm{c} 1 \mathrm{Ncs}}\right)$. Cone tip resistance were normalized to the equivalent values of overburden stress at $1 \mathrm{~atm}$. The SPT parameters 
analyzed herein include measured field blowcounts (N), normalized SPT blowcount $\left(\left(\mathrm{N}_{1}\right)_{60}\right)$, and equivalent clean sand normalized SPT blowcounts $\left(\left(\mathrm{N}_{1}\right)_{60 c s}\right)$. The shear wave velocity parameters analyzed herein include measured field shear wave velocity $\left(\mathrm{V}_{\mathrm{s}}\right)$, and normalized shear wave velocity $\left(\mathrm{V}_{\mathrm{s} 1}\right)$.

The CPT in-situ method is the focus of this analysis, with emphasis on the influence of fines content (FC), plasticity index (PI), and soil behavior type of $\mathrm{q}_{\mathrm{c} 1 \mathrm{~N}}$ data and CRR values. Recently the cone penetration test (CPT), has seen increased use in the Pacific Northwest. Despite the availability of the CPT for decades, use of the CPT in predicting liquefaction behavior of silty soils is limited. The value of the CPT is well-described by the The National Academy of Sciences paper "State of the Art and Practice in the Assessment of Earthquake-Induced Soil Liquefaction and Its Consequences" (NRC 2016). The report recommends that the data from the CPT for field-based estimates of liquefaction resistance be used where feasible and says the following, "CPT soundings offer advantages over other methods of estimating liquefaction resistance in detecting thin layers that may affect liquefaction triggering and subsequent pore-pressure redistribution. CPT results are less dependent on the equipment operator or setup than most other in situ test methods, and the CPT can be performed with relative speed and economy". Given the advantages of the CPT, this research aims to improve methods for using the CPT in the Pacific Northwest. 
While the CPT is the focus of this analysis, the SPT and $V_{s}$ was also analyzed. The SPT remains a common geotechnical site investigation method since there are established interpretation methods (e.g. Idriss \& Boulanger 2008) and it yields a soil sample for classification. It is also common for the shear wave velocity measurement from the field to be used in liquefaction triggering analyses. $V_{s}$ triggering relationships have been developed such as Andrus and Stokoe (2000) for sands.

This thesis first gives a general overview of how in-situ test data were extracted from geotechnical project data. Specifically, this thesis extracts in-situ testing results that correspond to intervals over which sampling and laboratory testing was performed. A detailed summary of the projects included in this analysis is included in the Appendix. Then the in-extracted in-situ test data are compared to the cyclic soil data extracted by Professor Khosravifar. Preliminary analyses are performed to look at qt-CRR relationships and how the relationship is affected by FC, PI or soil behavior index. Then a short summary of preliminary relationships between CRR-N160 and CRR-Vs are presented. 
In-Situ Data

This research required estimation of representative in-situ test values for soil that was also sampled and tested under cyclic loading. Data from CPT, SPT, and seismic shear wave velocity were analyzed from geotechnical project reports shown in the Appendix, Table 1. This section addresses each of these site investigation methods. For each method, a brief overview of the test procedure is provided followed by the general approach for estimating representative test values for sampled soils.

CPT

Cyclic samples from each site were obtained from explorations separate from the CPT tests. The following approach aimed to balance uncertainties in sub-surface characterization and sub-surface variability by estimating reasonable in-situ test values. Since available data for each site varied, the following provides a general approach to evaluating in-situ values. The approach for estimating representative values and samples was as follows:

- Sampled soil and CPT data should be from the same geologic unit. This required understanding general site stratigraphy and geologic deposition history. If the provided report included an interpreted soil profile, then this would be relied upon for site stratigraphy. Otherwise, a review of boring logs, CPT profiles, and laboratory index test data would be evaluated to see if there was consistency 
between soil classification properties and CPT-interpreted stratigraphy. Figure 1 shows CPT data profiles with interpreted soil stratigraphy according to the Unified Soil Classification System (USCS); all Shelby tube samples from the project appear to have been obtained from the silt (ML) unit.

- CPT profiles should be located close to the sample location. It was considered that the greater the distance between the sampling exploration and the CPT, the less likely CPT data represented sampled soil properties. Exceptions for distance were be made if the site has sufficient exploration data that shows uniform soil properties throughout the exploration area. over a large area that can be paired with decent confidence. If there was an offset in depth below the ground surface between the sample and the CPT data, then the CPT data were stress-normalized to the sampling depth. For some of the cyclic samples in the database, CPT parameters were unable to be assigned due to horizontal and/or vertical spatial distances between the explorations and CPTs that were too large to reliably assign CPT test values.

- CPT interpretation should consider effects of interlayered materials. Many CPT profiles showed profiles that were interbedded with silt/clay and sand lenses. This results in peaks and troughs in the CPT data. Ahmadi \& Robertson (2005) show that measured $q_{t}$ in stiff soil layers will be less than the "true" $q_{t}$ values due to the influence of nearby soft soil layers. An example of this is shown in Figure 1. Four CTX samples were taken from an interbedded silt deposit. The CPT was estimated 
to be performed less than 10-feet away from the sampled location, therefore, there was reasonable confidence that the soils were similar between the CPT profile depth and sampling depth. The depths from which the samples were taken were plotted in the CPT profile to determine where the sampled point lies in reference to the CPT profile. In Figure 1, the CTX samples lie in the low and peaks of tip resistance values for that deposit, requiring analyzing index test data to determine which CPT values are indicative of that sample at that depth. Index tests revealed that the bottom two samples were non-plastic silts and the upper two samples were medium plasticity silt. Therefore, the non-plastic silts were represented by the peak $q_{c}$ values, and the medium plasticity silts were represented by the trough $q_{c}$ values. Although, the measured $q_{c}$ values in the nonplastic silt are likely lower than the true value, choosing the higher $q_{c}$ values was considered the more reasonable path forward compared to averaging qc values. Future work will re-evaluate these qc values with thin-layer corrections (e.g. Boulanger \& DeJong 2018).

Once it was determined that CPT data were reasonably paired with sampling intervals, various CPT parameters (defined below) were determined.

For sites where tip resistance, skin friction, and pore pressure CPT profiles were provided, the following CPT parameters were developed: $q_{t}=$ corrected tip resistance, usually 
provided in the CPT plots/data. Usually in English tsf units. Used for development of CRR relationship.

- $\mathrm{q}_{\mathrm{c}}=$ uncorrected tip resistance, calculated as a supplement for possible future research and not discussed further in this dissertation. Usually in English tsf units.

- $\mathrm{f}_{\mathrm{s}}=$ skin friction, usually provided in the CPT plots/data. Sometimes the friction ratio $\%\left(f_{s} / q_{t}\right)$ was provided instead of the skin friction, which was used to back-calculate the skin friction with available $q_{t}$. Usually in English tsf units.

- $\mathrm{Q}=$ normalized cone penetration resistance (Robertson 1990), unitless.

- $\mathrm{F}=$ normalized friction ratio (Robertson 1990), in \%.

- $\mathrm{I}_{\mathrm{c}}=$ Soil Behavior Type Index (Robertson 1990), unitless. An important parameter in identifying soil behavior type (SBT) and estimating the liquefaction susceptibility of a soil. Current practice estimates that a soil with $I_{c}>2.6$ is not susceptible to liquefaction, where an $I_{c}<2.6$ indicates that the soil is susceptible to liquefaction.

- $\mathrm{B}_{\mathrm{q}}=$ normalized pore pressure parameter (Robertson 1990), unitless.

- $\quad \mathrm{q}_{\mathrm{c} 1 \mathrm{~N}}=$ normalized and corrected tip resistance (Idriss and Boulanger 2008), unitless. Used for development of CRR relationship. 
- $\quad \mathrm{q}_{\mathrm{c} 1 \mathrm{Ncs}}=$ equivalent clean sand normalized and corrected tip resistance (Idriss and Boulanger 2008). Determined by applying the clean sand correction for FC from Idriss and Boulanger (2014) to $q_{\mathrm{c} 1 \mathrm{~N}}$.

CPT values were chosen in two ways for this research. The first method was using provided tabulated CPT data. These data were then used to create CPT plots. This method was preferred since CPT plots and samples could easily be plotted with one another to analyze subsurface stratigraphy and CPT parameters. The second method was to visually pick the representative CPT with the use of a graph digitizer using the CPT plots provided in the database project data. Using the graph digitizer was useful for most sites, however where sites had very low CPT values, the calculated normalized parameters can become very sensitive to slight changes in values and therefore erroneous. Great care was taken to ensure that the visually picked CPT data was sufficient for pairing. Sensitivity occurred when the measured tip resistance was close the total stress at that point.

The use of the $\mathrm{FC}(\mathrm{FC})$ of soil in determining the liquefaction resistance of clean sands has been developed by Idriss and Boulanger (2014) and others for non-plastic soils. The soils in analyzed in this dissertation most often have a FC greater than $35 \%$ which is identified by Idriss and Boulanger (2008) as having its behavior dominated by its fines fraction. Most cyclic samples analyzed in this dissertation had P200 washes (FC) performed, however some samples did not. In the cases where P200 washes were not performed and CPT data was available, the FC correlation suggested by Idriss and Boulanger (2014) was used to 
estimate the FC. The equation requires the SBT index Ic and a fitting parameter $\mathrm{C}(\mathrm{FC})$. The $\mathrm{C}(\mathrm{FC})$ value used in this dissertation is 0 . Figure 2 shows the $\mathrm{FC}$ from the database plotted against Ic from the database for the projects analyzed in this research. There are also five data points of Idriss and Boulanger (2014) CPT CF which were used when no P200 wash data was available.

CPT tip resistance data mentioned throughout this dissertation will be reffered to as $q_{c}$, unles referring secifically to $\mathrm{q}_{\mathrm{t}}$, the corrected cone tip resistance. This $\mathrm{q}_{\mathrm{c}}$ annotation was selected based on the conventional CPT tip resistance annotation from Idriss and Boulanger (2014), in order to maintain consistency with the triggering relationships also suggested by Idriss and Boulanger (2014). 

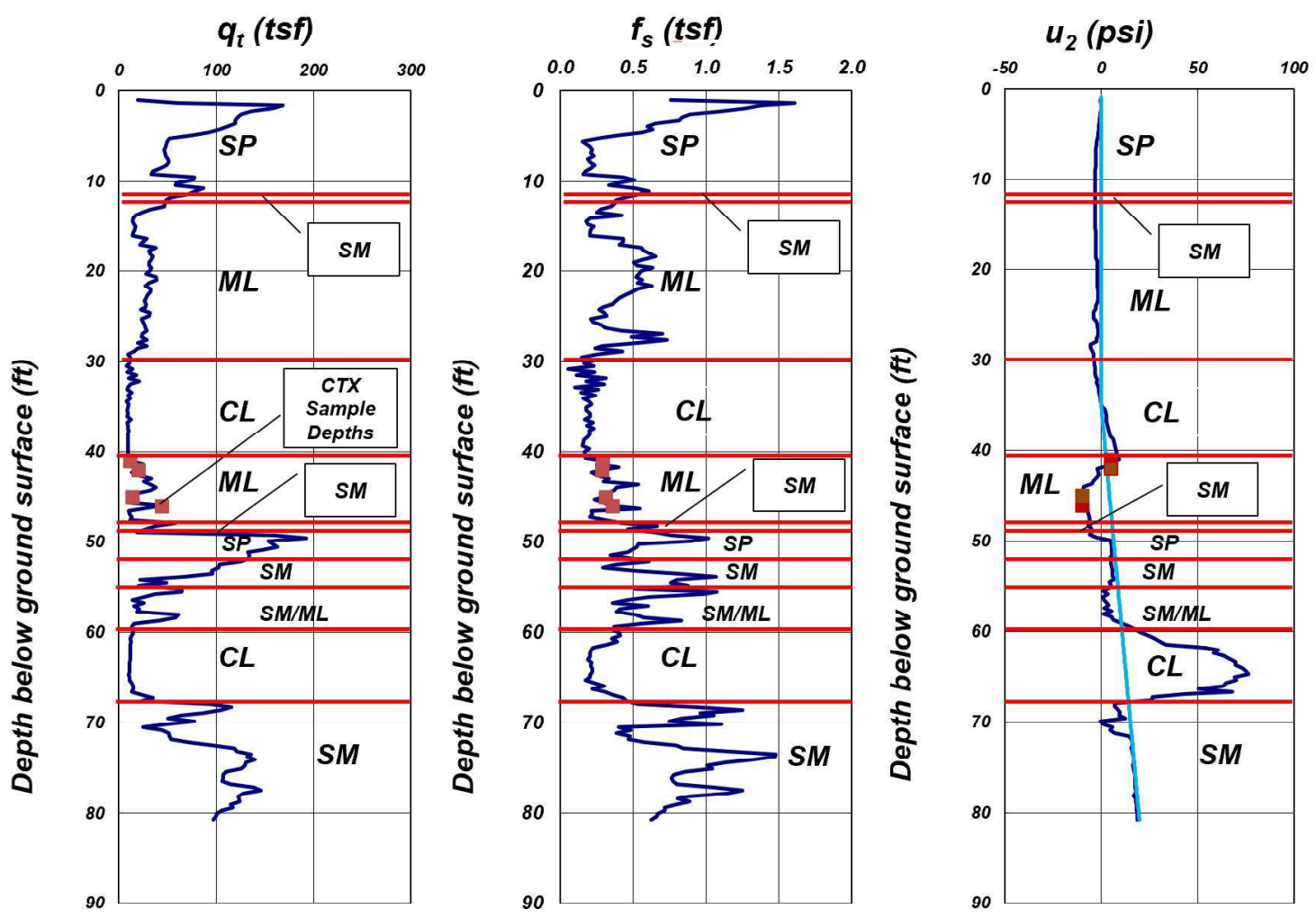

Figure 1. CPT-3C profile from project 0-05. The samples were taken from exploration B3-C nearby. 


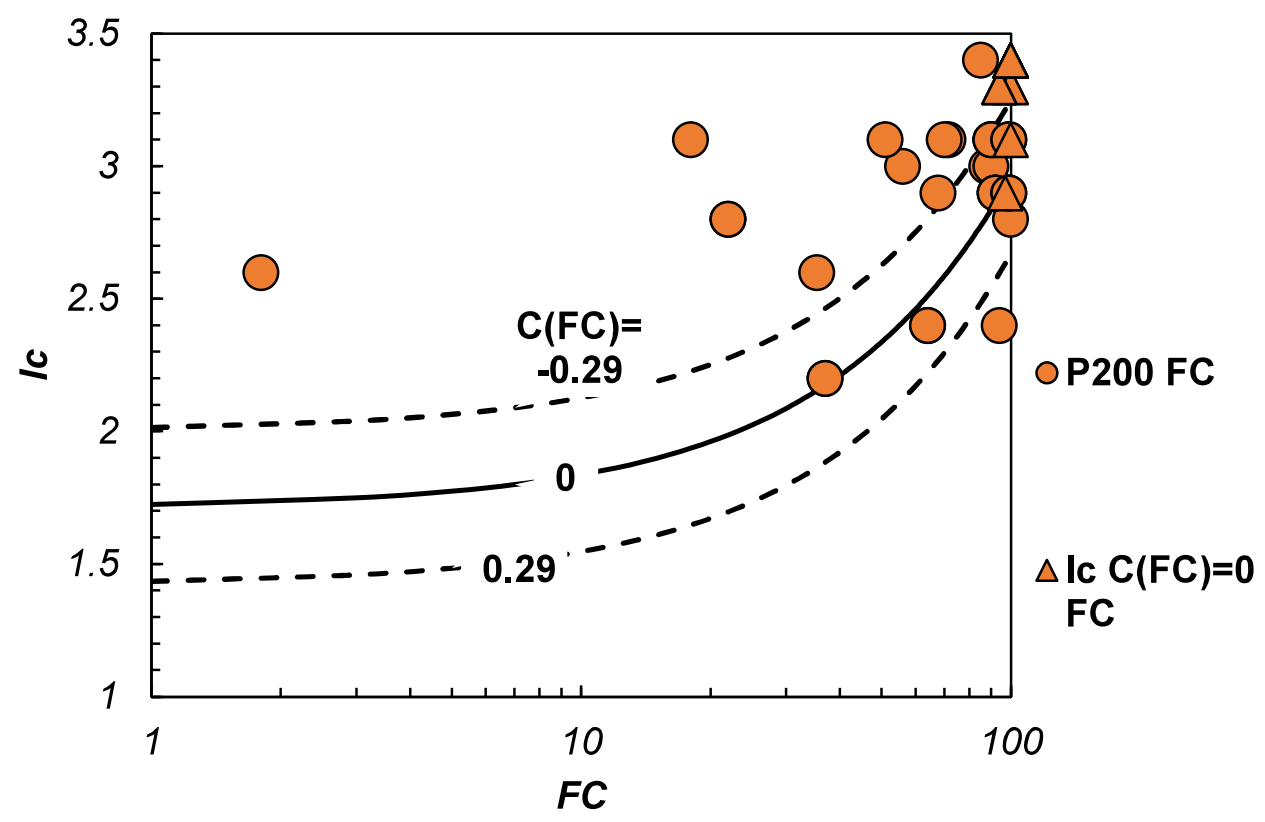

Figure 2. Database FC versus SBT Index from Idriss and Boulanger (2014).

Figure 3 from Robertson (2009) contains the project CPT data plotted along with Ic lines. Note that most of the data falls below the 2.6 line with SBT index values mainly clustering near the 2.95 line. Only 4 samples fell above the 2.6 line with SBT index values lower than 2.6. The SBT value of 2.6 is commonly considered in practice to be the cutoff value for non-liquefiable soil to liquefiable soils, with $\mathrm{I}_{c}<2.6$ being liquefiable (i.e., cyclic failure by excess pore pressure generation and effective stress approaching zero) and $I_{c}>2.6$ being non-liquefiable (i.e., cyclic failure by cyclic softening). 


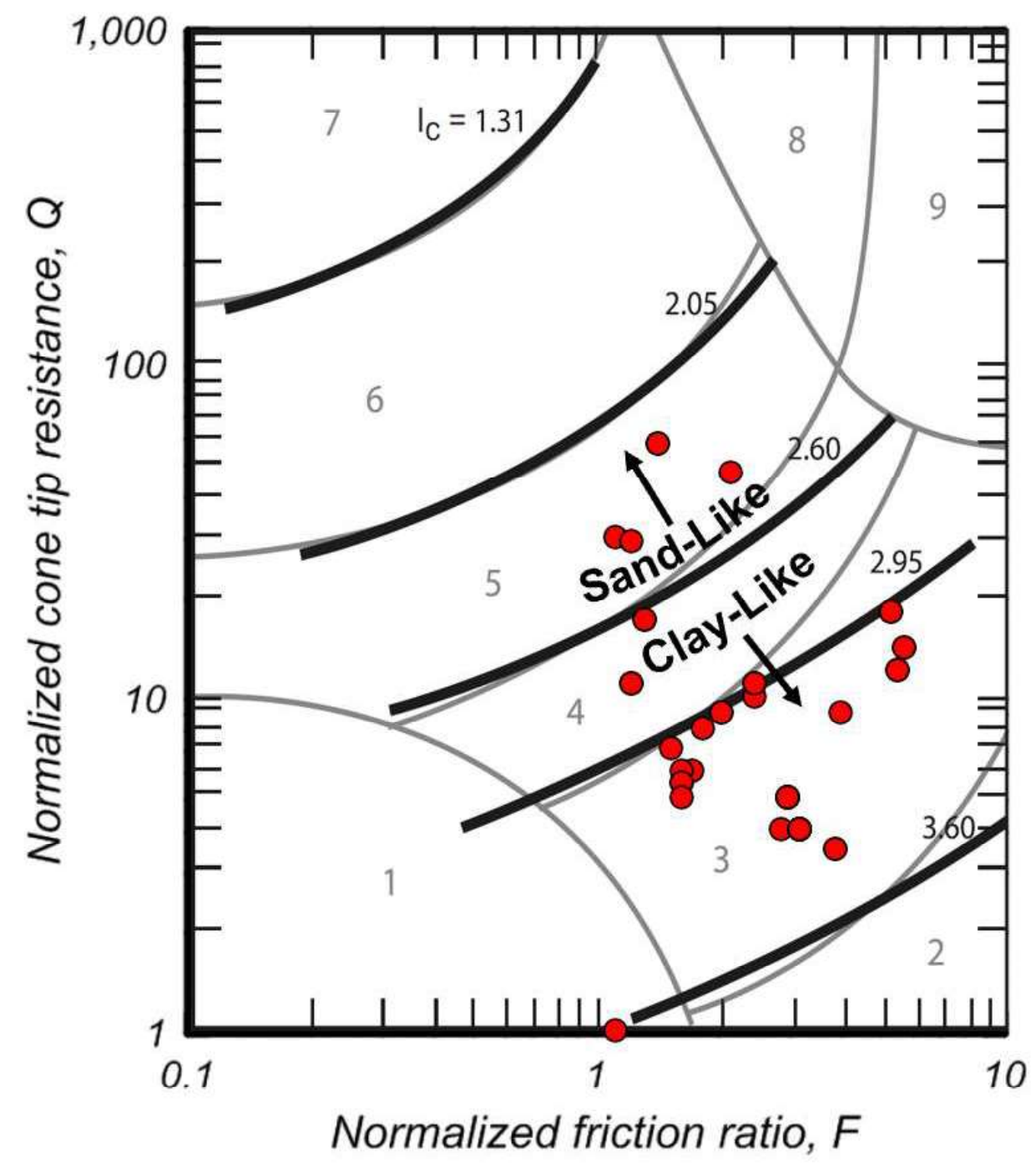

1. Sensitive, fine grained

2. Organic soils - peats

6. Sands - clean sand to silty sand

3. Clays - silty clay to clay

4. Silt mixtures - clayey silt to silty clay

7. Gravelly sand to dense sand

5. Sand mixtures - silty sand to sandy silt

8. Very stiff sand to clayey sand *

9. Very stiff, fine grained *

${ }^{*}$ Heavily overconsidated or cemented

Figure 3. CPT data from Oregon and Washington analyzed in this research. Figure from Robertson (2009). 
SPT

Cyclic samples from each site were often sampled in borings where SPTs were performed. Typically, SPTs were performed directly after the Shelby tube extraction; in these cases, where the SPT was performed in the same geologic unit, the $\mathrm{N}$ value was determined from that SPT. In other cases, SPTs were performed above the Shelby tube sample. Like the first method, the $\mathrm{N}$ value above the Shelby tube was used for that sample if geologic conditions are similar. In some cases, the SPTs are not vertically near the sample elevation, but a range could be estimated based on boring log interpretation and bracketing $\mathrm{N}$ values above and below the sample elevation.

Hammer efficiency data was not often available. In these cases, an estimated hammer efficiency of $80 \%$ was used. Idriss and Boulanger (2008) was used to process the SPT data and calculate the necessary parameters. Where P200 washes (FC) tests were not performed, FC was estimated with available boring log, laboratory, and CPT data. The following SPT data was developed:

- $\quad \mathrm{N}=$ The number of blows from a 140-pound hammer dropped from a height of 30 inches required to advance the sampler the final 12 of the 18-inches driven.

- $\left(N_{1}\right)_{60}=$ The normalized $N$ value corrected for $60 \%$ hammer efficiency. 
- $\left(\mathrm{N}_{1}\right)_{60 c s}=$ equivalent clean sand normalized and corrected $\mathrm{N}$ value (Idriss and Boulanger 2008). Determined by applying the clean sand correction for FC from Idriss and Boulanger (2008) to $\left(\mathrm{N}_{1}\right)_{60}$.

Figure 4 shows a boring from project W-09 where SPTs were performed along with sampling. At a depth of 7 feet a Shelby tube was pushed to 9 feet bgs. After the Shelby tube was extracted from the borehole, an SPT test was performed at 9 feet bgs and yielded a SPT blowcount of 0 . At a depth of 40 feet a Shelby tube was pushed to 41 feet bgs. After the Shelby tube was extracted from the borehole, an SPT test was performed at 41 feet bgs, and yielded a SPT N blowcount of 5 . These blowcounts assigned to the cyclic samples at sample depths of 8.7 and 40.3 feet bgs. 


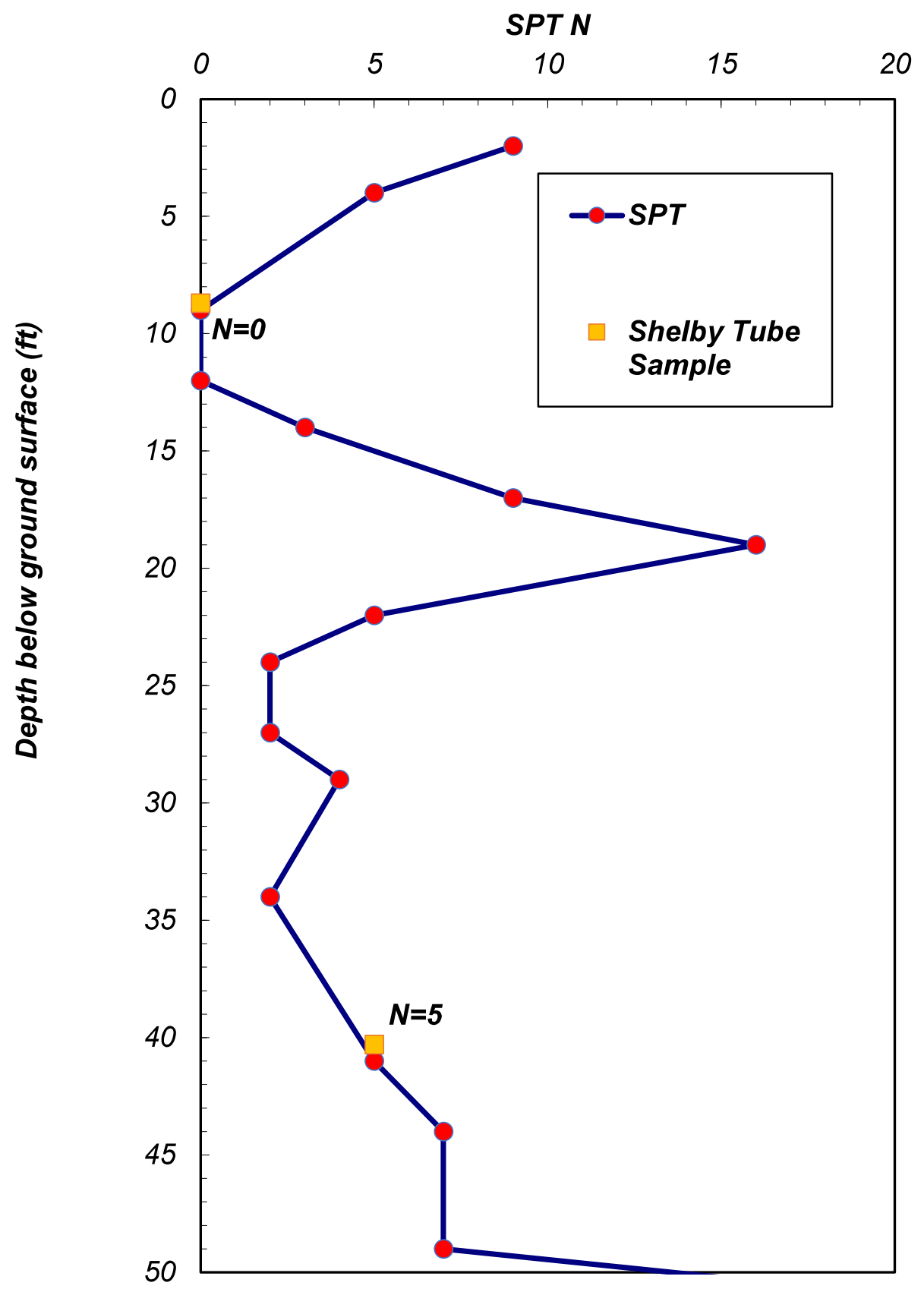

Figure 4. SPT profile from project W-09, boring H-45-07. 


\section{Shear Wave Velocity}

Shear wave velocity data was analyzed by both New Albion Geotechnical, LLC for some project sites as well as in this research. Shear wave velocity measurements were made from either down-hole, seismic CPT, or suspension logging methods. Some sites contained shear wave velocity data from multiple methods. In these cases, the results from the different methods were compared and the resulting method judged to best represent the sample was selected. In cases where downhole seismic tests were performed in the same borehole which the cyclic samples were obtained, these values were used since the data was obtained from that exploration. In cases where downhole methods were not used, representative values were estimated using the guidance outlined above. Figure 6 shows a boring log from project W-02 where cyclic samples were cyclic samples were taken from the Shelby tube pushed from 30 to 32 feet bgs. The boring log has the SPT N values and shear wave velocities plotted with depth. In this case, shear wave velocity in the range of sample depths was judged by New Albion Geotechnical, LLC to be 338 feet per second. This value is in accordance with the procedures outlined above and was determined to be acceptable. 


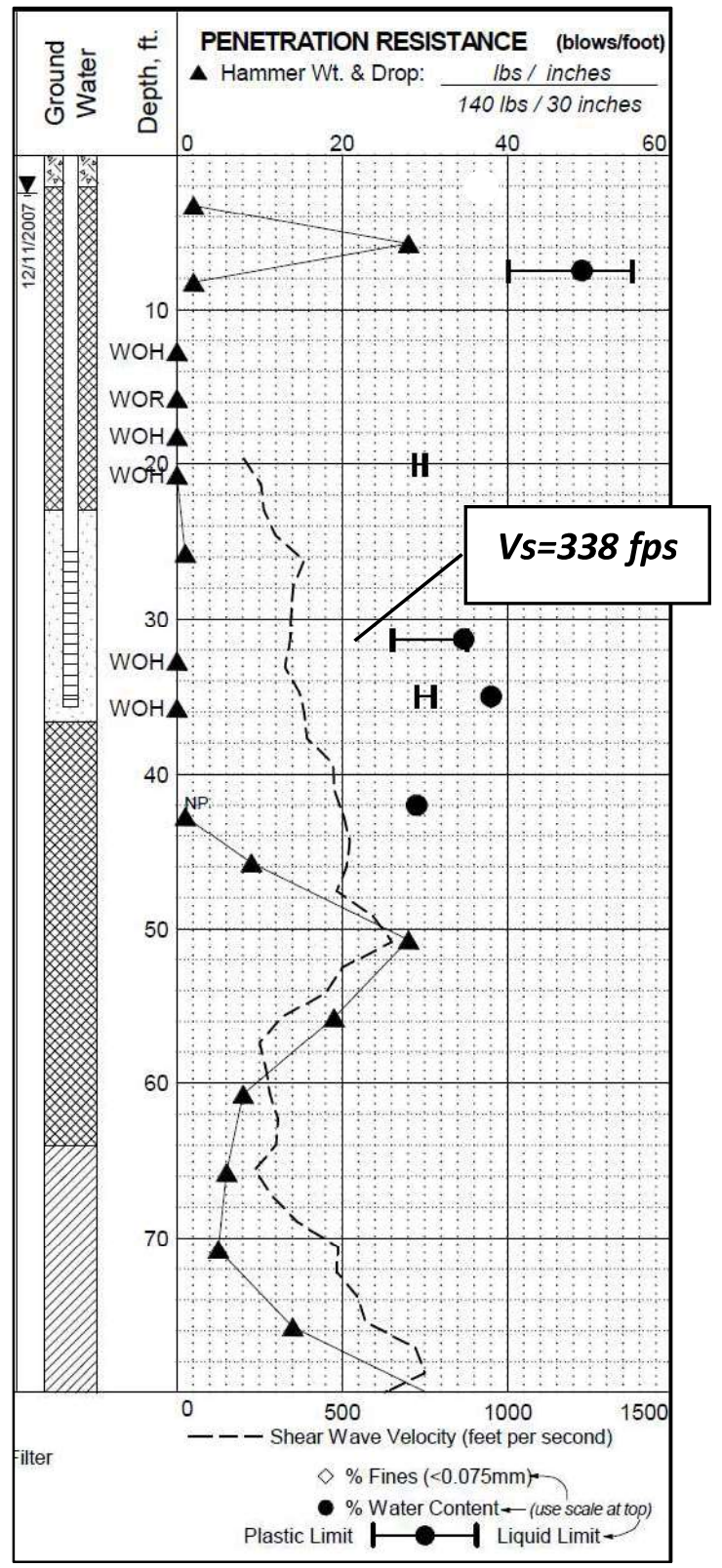

Figure 5.Boring log excerpt from project W-02 . 
$\mathrm{q}_{\mathrm{c}}$-CRR Relationships from the Database

CPT cone tip resistance is presented as $q_{c}$ in this paper. $q_{t}$ is the cone tip resistance corrected from the measured cone tip resistance $\left(q_{c}\right)$ to account for pore pressures at the shoulder piezo element. $q_{t}$ values were assigned to samples and plotted with the determined CRR normalized to a $M=7.5$ event $\left(C R R_{M=7.5}\right)$. Relationships were also presented for $q_{c 1 N}$ and $q_{c 1 N c s}$, with a focus on $q c 1 N$. Normalizing of the data was necessary to interpret that cone tip resistance data at equivalent stress states and to utilize existing triggering methods Figures 6 through 8 contain plots of all CPTu data points with measured and normalized cone tip resistance values versus CRR. These data were then analyzed based on varying factors such as FC, PI, and Ic in the following sections.

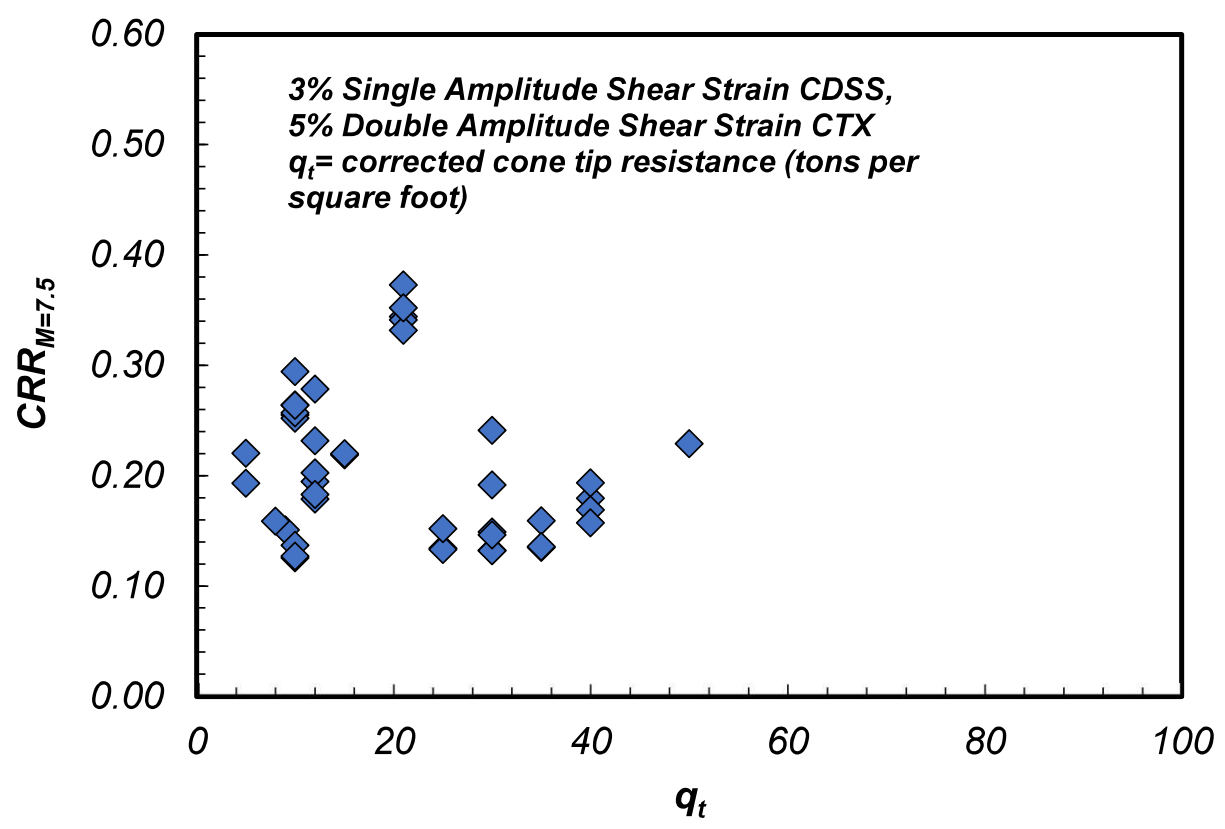


Figure 6. Corrected $\mathrm{q}_{\mathrm{c}}$ data plotted against laboratory determined CRR normalized to a Magnitude 7.5 earthquake.

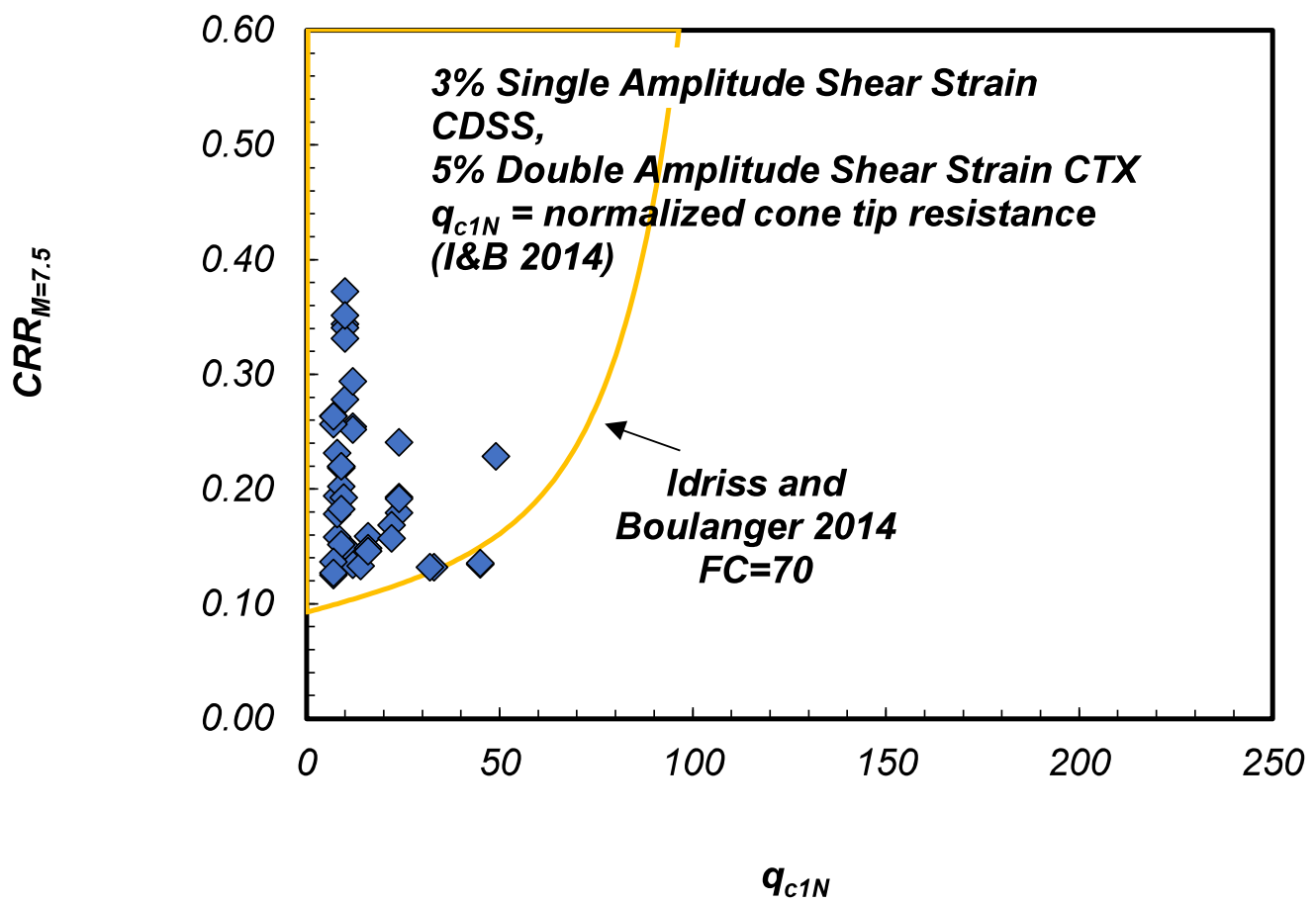

Figure 7.Normalized $\mathrm{q}_{\mathrm{c}}$ data plotted against CRR normalized to a Magnitude 7.5 earthquake. 


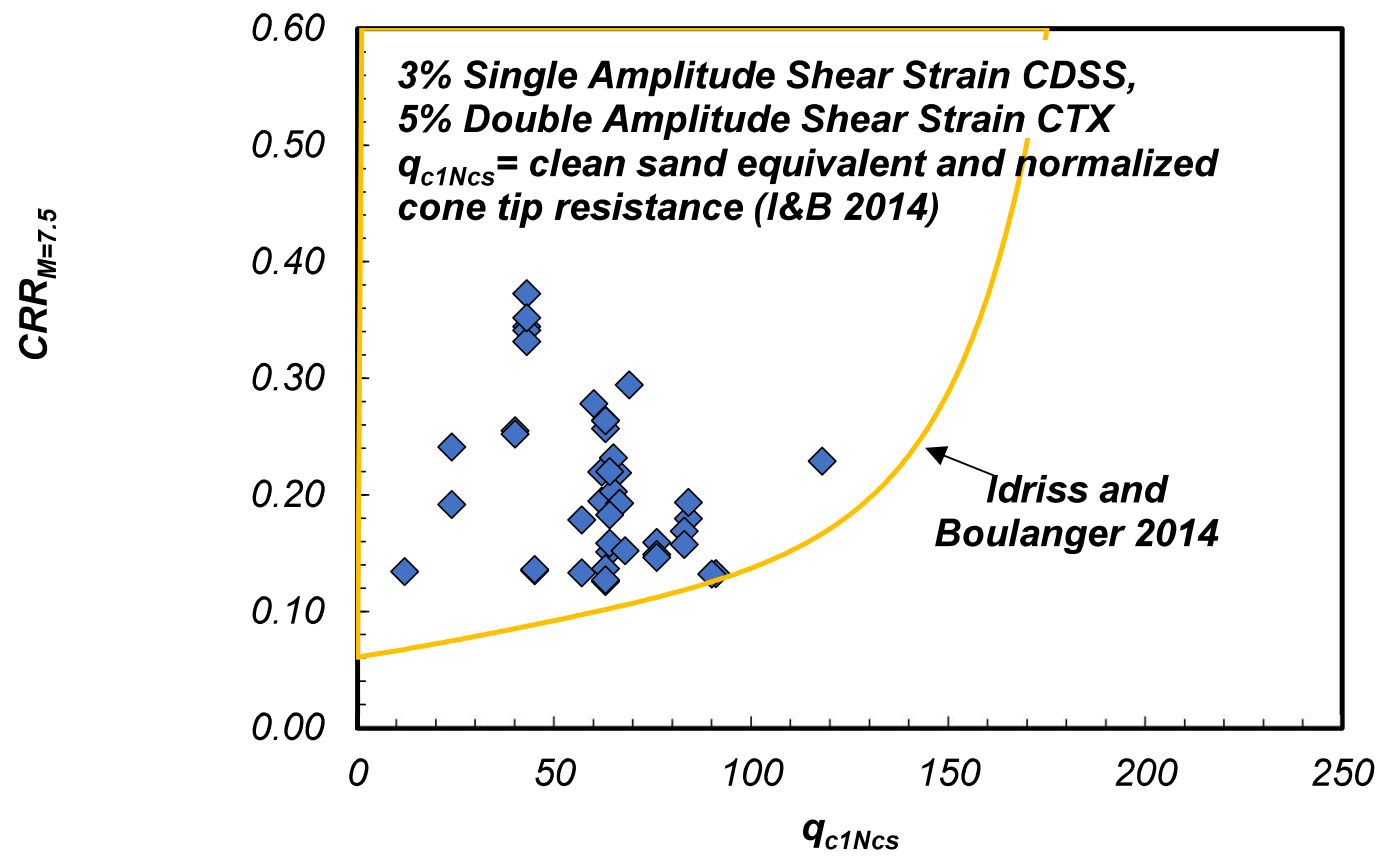

Figure 8. Equivalent clean sand normalized $q_{c}$ data plotted against CRR normalized to a Magnitude 7.5 earthquake. 
Role of $\mathrm{FC}$ in $\mathrm{q}_{\mathrm{c}}-\mathrm{CRR}$

To evaluate the influence of $F C$ on $\mathrm{q}_{\mathrm{c}}-\mathrm{CRR}$ relationships, samples were categorized into multiple ranges of FC. The FC intervals were based on the deterministic in-situ CRR relationships from Idriss and Boulanger (2014) and seen in Figure 9. Additionally, FC are analyzed at ranges of $71-80,81-90$, and $91-100$ to screen for any sensitivity as FC greater than 70. The relationship from Idriss and Boulanger (2014) was developed using soils that had sand-like behavior. However, most of the samples in this study consist of soils with PI that indicates clay-like behavior sand may not necessarily be applicable to the deterministic triggering methods. Future research will address this question.

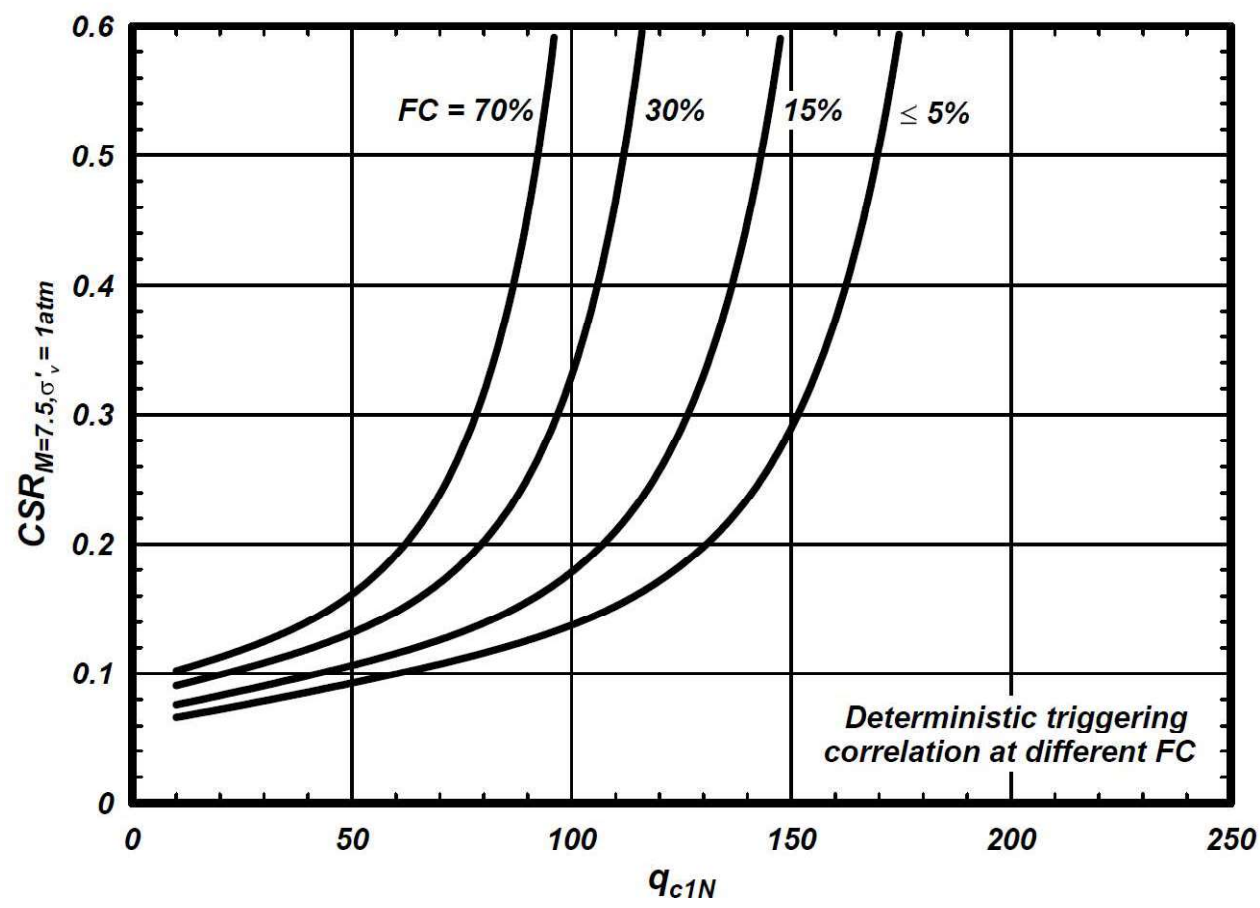

Figure 9. Deterministic triggering of sand-like behavior by FC from Idriss and Boulanger (2014). 


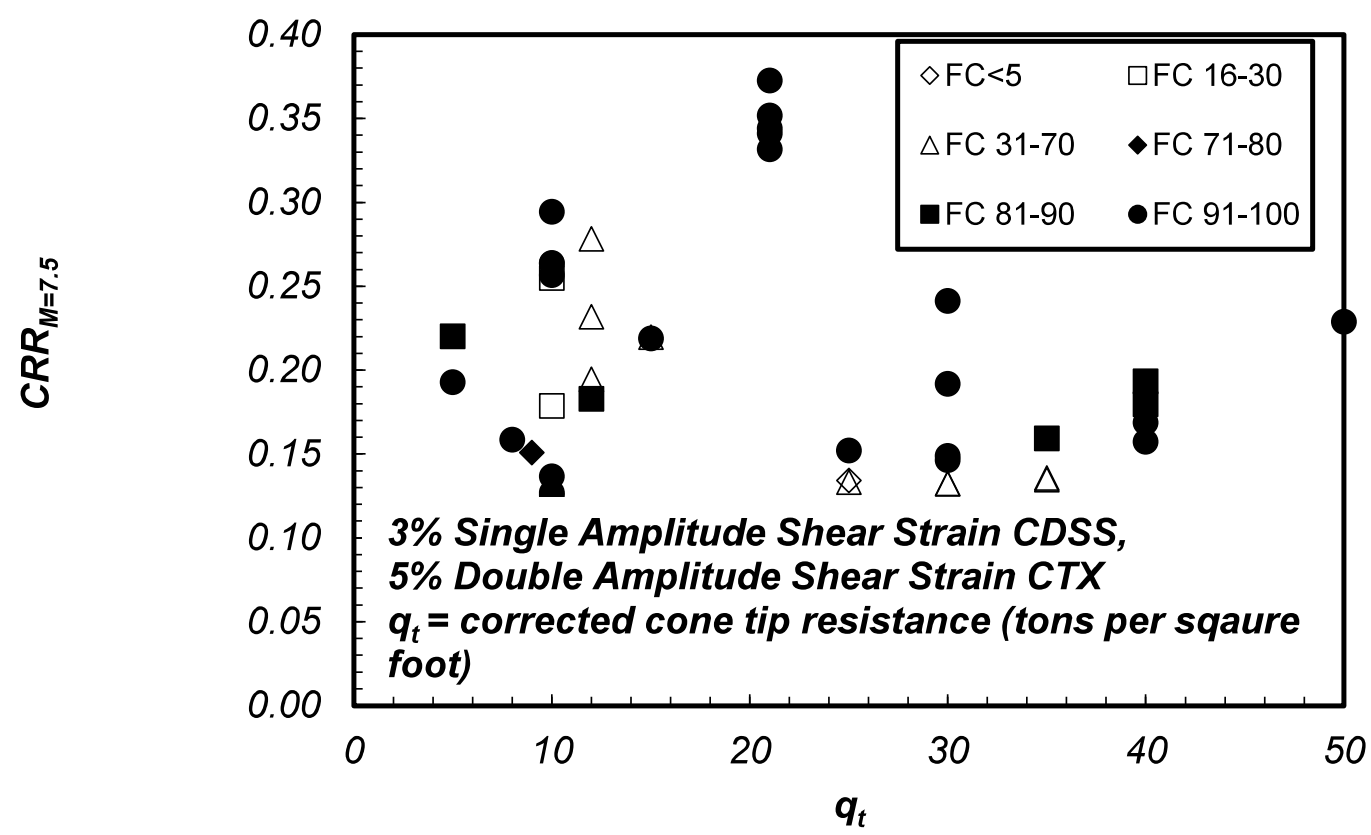

Figure

10. Corrected $\mathrm{q}_{c}$ data played against CRR and categorized by FC.

$\mathrm{q}_{\mathrm{t}}$-CRR data are plotted in Figure 10. Samples possessing $\mathrm{FC}$ greater than 70 fall within $\mathrm{q}_{\mathrm{t}}$ values ranging from 5 to 50 tsf and have CRRs ranging from 0.13 to 0.37 . Samples possessing $\mathrm{FC}$ of 70 or less fall within $\mathrm{q}_{\mathrm{t}}$ values ranging from 10 to 35 tsf and CRRs ranging from 0.13 to 0.28 .

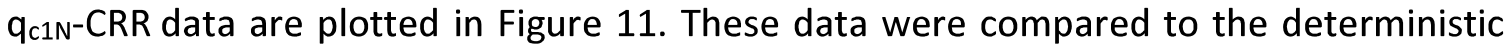
CRR- $\mathrm{q}_{\mathrm{c} 1 \mathrm{~N}}$ line for $\mathrm{FC}$ of70 from Idriss and Boulanger (2014) is shown in Figure 10. Except for one data point $\left(q_{\mathrm{c} 1 \mathrm{~N}}=49 \mathrm{tsf}, \mathrm{CRR}=0.22\right)$, all samples possessing $\mathrm{FC}$ greater than 70 fall within $q_{\mathrm{c} 1 \mathrm{~N}}$ values ranging from 7 to 24 and have CRRs ranging from 0.13 to 0.37 . . Samples possessing $\mathrm{FC}$ of 70 or less fall within $\mathrm{q}_{\mathrm{c} 1 \mathrm{~N}}$ values ranging from 8 to 45 and CRRs ranging from 0.13 to 0.28 . 


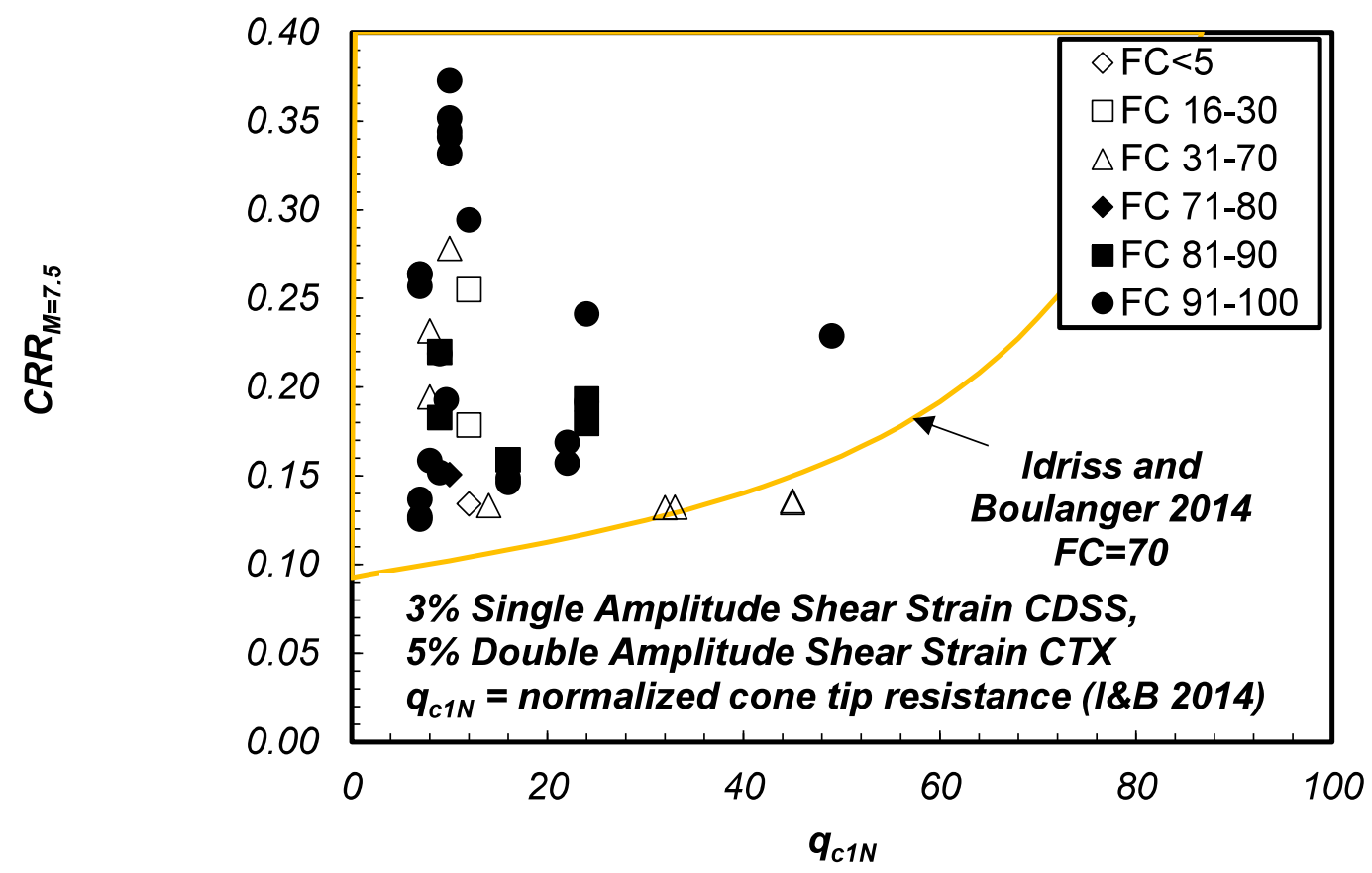

Figure 11. Normalized $\mathrm{q}_{\mathrm{c}}$ data plotted against CRR and categorized by FC.

These data do not show a strong relationship to FC. Variation in FCFC over relatively narrow range was observed often in the CPT profiles for many projects included in this research; for example, this was observed in projects $0-05,0-07,0-12$, and $W-13$. At these sites, the CPT profiles display peaks and troughs on the $q_{t}$ plots as CPT advances through sandy and silty layers with higher and lower $q_{t}$ values, respectively. This suggests that there may be a clearer relationship between the FC and CRR, however the samples would need to be carefully selected when choosing what soil is the best representation of the cyclic sample within the Shelby tube.

Equivalent clean sand normalized $q_{c}$ data were determined from the previously mentioned methods for each data point. The equivalent clean sand value is used to 
evaluate the liquefaction resistance of sands accounting for the added resistance of FC. For this analysis, the equivalent clean sand data was only considered for material with PI less than 7 in accordance with sand-like behavior and susceptible to liquefaction from Idriss and Boulanger (2006). Additionally, the plotted data have Ic values of 2.05 to 2.6 to represent sand-like material susceptible to liquefaction from Robertson and Wride (1998) All data points plotted slightly above the Idriss and Boulanger (2014) CRR line. This indicates that existing $q_{c}-C R R$ triggering relationship from Idriss and Boulanger (2014) may reasonably represent conservative behavior of these sand-like soils.

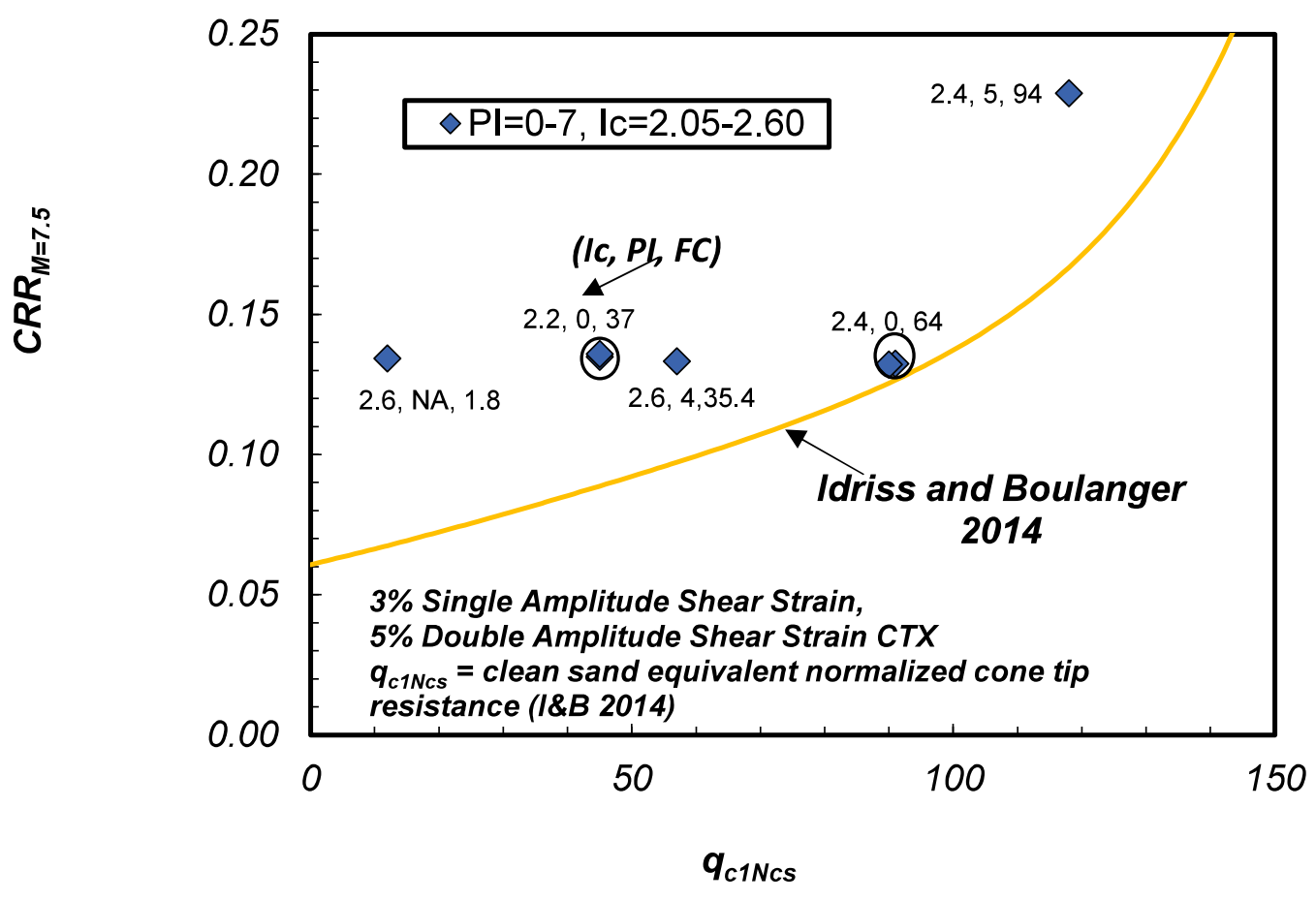

Figure 12. Equivalent clean sand normalized $q_{c}$ data categorized into sand-like behavior. 
Role of PI in $\mathrm{q}_{\mathrm{c}}$-CRR Relationships

PI data were available for select samples. Current liquefaction triggering methods include the PI as a means of determining whether the soil is susceptible liquefaction failure susceptibility (e.g. Idriss \& Boulanger 2006). For samples where PI was determined, the PI was labeled along with the FC to further study the effects of both FC and PI on the qt-CRR relationship. Other samples with no PI data were also plotted with their FC shown for comparison to data with PI's.

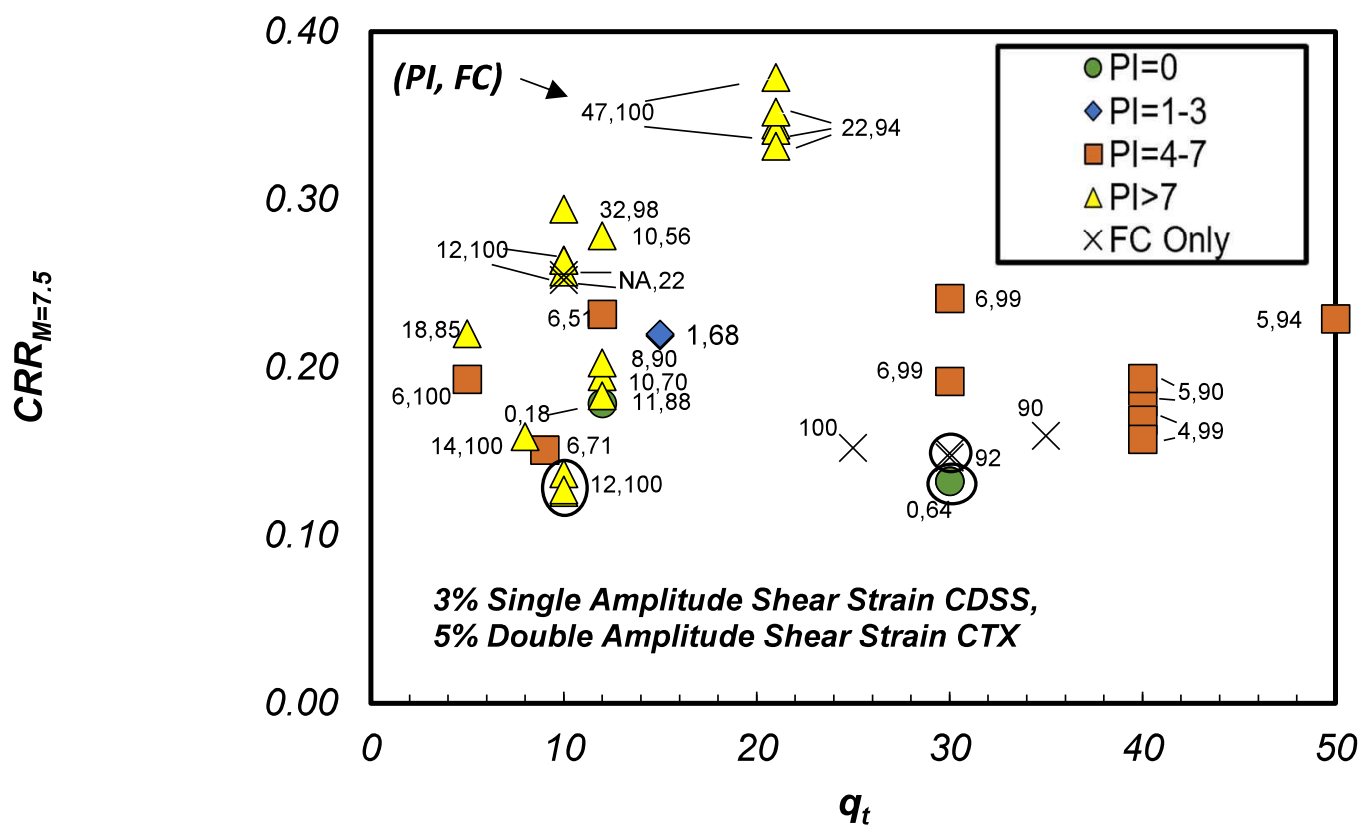

Figure 13.Corrected $\mathrm{q}_{\mathrm{c}}$ data plotted against-CRR data with PI and FC labels.

Idriss and Boulanger (2006) suggested that materials with a PI less than 7 are susceptible to liquefaction and exhibit sand-like behavior, and materials with PI greater than 7 are susceptible to cyclic softening and exhibit clay-like behavior. They also suggest that a 
transition zone from sand-like to clay-like behavior at PI ranging from 3 to 7 . The data herein was categorized as $0,1-3,4-7$, and greater than 7 . With the aim of screening for any sensitivity at PI less than 7 .

From Figures 13 and 14, some trends become evident once the samples are characterized by PI. Data with $\mathrm{PI}=0$ (non-plastic fines) plotted on the relatively lower end of the CRR ranges, at 0.13 to 0.18 , with $q_{t}$ ranging from 12 to 30 tsf. One data point fell within the $\mathrm{PI}$ range of 1-3, with a $q_{t}$ of 15 tsf and CRR of 0.219. Data with PI of 4-7 have $q_{t}$ values ranging from 5 to 50 tsf with CRR ranging from approximately 0.16 to 0.24. Data PI greater than 7 have $\mathrm{q}_{\mathrm{t}}$ ranging from 5 to $21 \mathrm{tsf}$, with CRR ranging from 0.13 to 0.37 .

Figure 14 plots the $\mathrm{q}_{\mathrm{c} 1 \mathrm{~N}-\mathrm{CRR}}$ relationship with $\mathrm{PI}$ and $\mathrm{FC}$ data. Data with $\mathrm{Pl}=0$ plotted on the relatively lower end of the CRR ranges at 0.13 to 0.18 with $\mathrm{q}_{\mathrm{c} 1 \mathrm{~N}}$ ranging from 83033 . One data point fell within the PI range of 1-3, with $\mathrm{q}_{\mathrm{c} 1 \mathrm{~N}}$ of 9 and CRR of 0.22 . Data with PI of 4-7 had $\mathrm{q}_{\mathrm{c} 1 \mathrm{~N}}$ ranging from 8 to 49 with CRR ranging from 0.16 to 0.24 . Data with PI less than 7 show no apparent trend with increasing $q_{\mathrm{c} 1 \mathrm{~N}}$ or CRR. However, data with PI greater that 7 have $\mathrm{q}_{\mathrm{c} 1 \mathrm{~N}}$ data ranges from 7 to 12 with CRR ranging from 0.13 to 0.37 . 


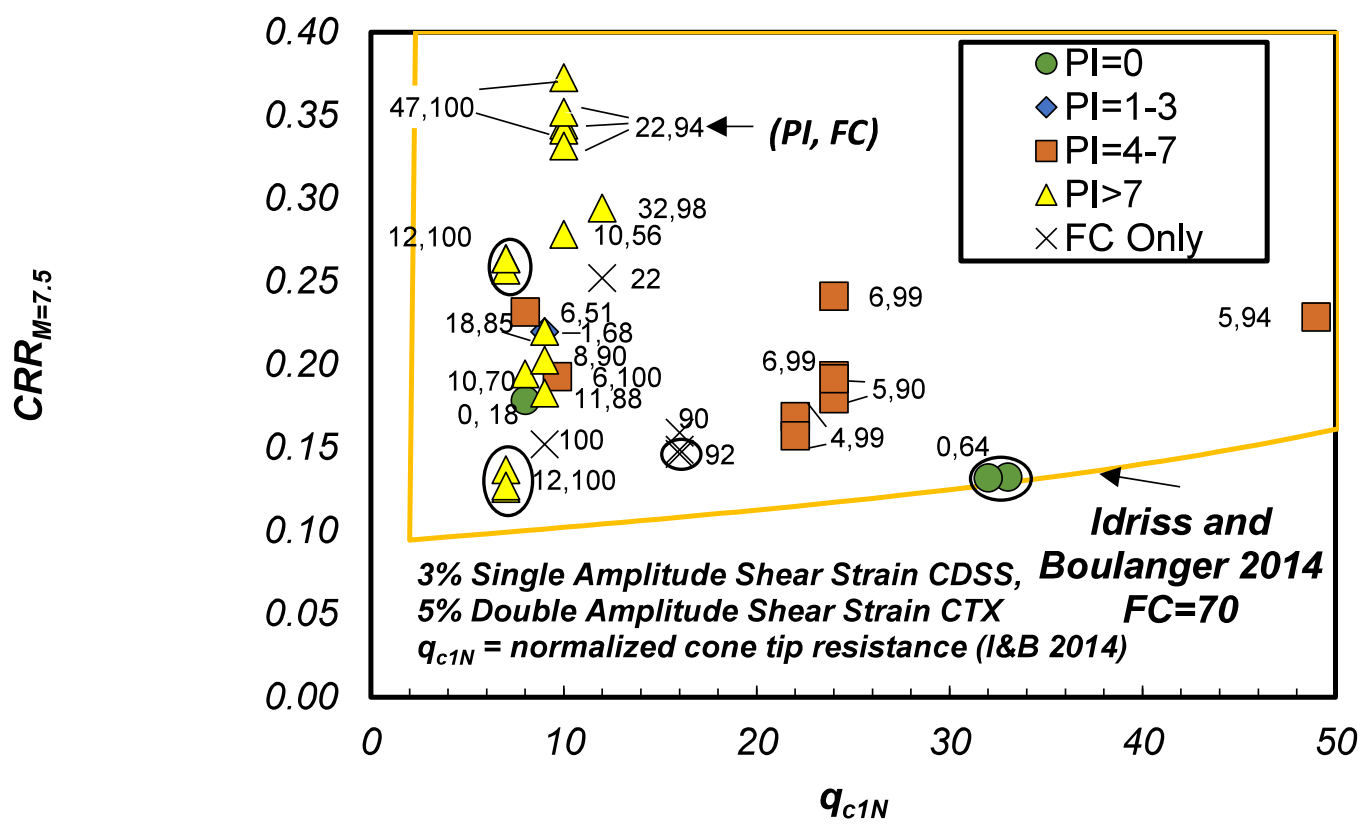

Figure 14. Normalized $\mathrm{q}_{\mathrm{c}}$ data plotted against CRR and categorized by PI and supplemented by FC. 
Role of Soil Behavior Index in $\mathrm{q}_{\mathrm{c}}-$ CRR Relationships

Sample data were categorized based on their calculated Ic values and the soil behavior type from Robertson (2009) as shown in Figure 15. The three soil behavior type zones analyzed were zones 3,4 and 5, with corresponding Ic ranges of 2.95-3.6, 2.60-2.96, and 2.05-2.6. Data with Ic $>2.95$ were represented by 26 datapoints, data with Ic between 2.6 and 2.95 were represented by 10 datapoints, and data with Ic of 2.6 or less were represented by 5 datapoints. In Figure 15, Ic values ranging from 2.05 to 2.6 have tip resistance values ranging from 25 to $50 \mathrm{tsf}$, with CRR ranging from 0.125 to 0.229 . Ic values ranging from 2.61 to 2.95 have tip resistance values ranging from 5 to 30 tsf, and corresponding CRR ranging from 0.14 to 0.29 . Ic values ranging from 2.96 to 3.6 have tip resistance values ranging from 1 to 26 tsf, and corresponding CRR ranging from approximately 0.13 to 0.37 . 


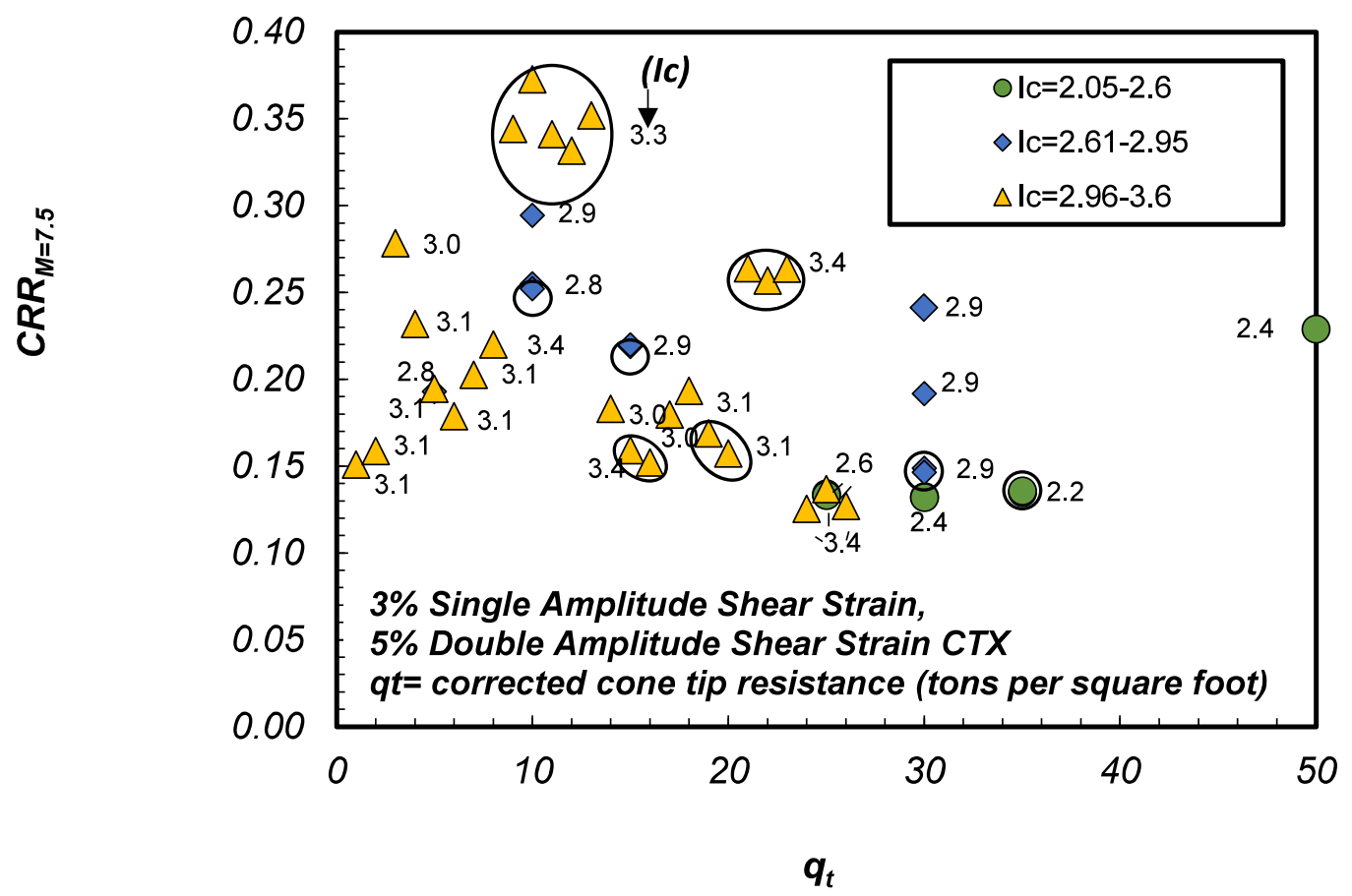

Figure 15. Corrected $\mathrm{q}_{\mathrm{c}}$ data plotted against-CRR and categorized by Ic.

To further evaluate the qt-CRR relationships the sample data were further categorized based on ranges of Ic values from Robertson (2010) as shown in Figure 16 as well as PI. The purpose of this categorization was to incorporate Idriss and Boulanger (2006) with Robertson (2009) to assimilate soil type and behavior. For example, data that was categorized with Ic ranging from 2.05 to 2.6, "Sand Mixtures", was also categorized with having a PI ranging from 0-7 "Sand Like". 


\begin{tabular}{c|c|c} 
Zone & Soil Behavior Type & $\boldsymbol{I}_{\boldsymbol{c}}$ \\
\hline 1 & Sensitive, fine grained & N/A \\
\hline 2 & Organic soils - clay & $>3.6$ \\
\hline 3 & Clays - silty clay to clay & $2.95-3.6$ \\
\hline 4 & Silt mixtures - clayey silt to silty clay & $2.60-2.95$ \\
\hline 5 & Sand mixtures - silty sand to sandy silt & $2.05-2.6$ \\
\hline 6 & Sands - clean sand to silty sand & $1.31-2.05$ \\
\hline 7 & Gravelly sand to dense sand & $<1.31$ \\
\hline 8 & Very stiff sand to clayey sand & N/A \\
\hline 9 & Very stiff, fine grained & N/A \\
\hline
\end{tabular}

Figure 16. Soil behavior type indices chart from Robertson (2010).

Samples were categorized with Ic values ranging from 2.05 to 2.6 and/or a PI less than 7, and Ic values greater than 2.6 and/or PI greater than 7. Samples that exhibit neither or both sand of the above criteria were put into a third category which contained data with Ic greater than 2.6 and PI less than 7 . 


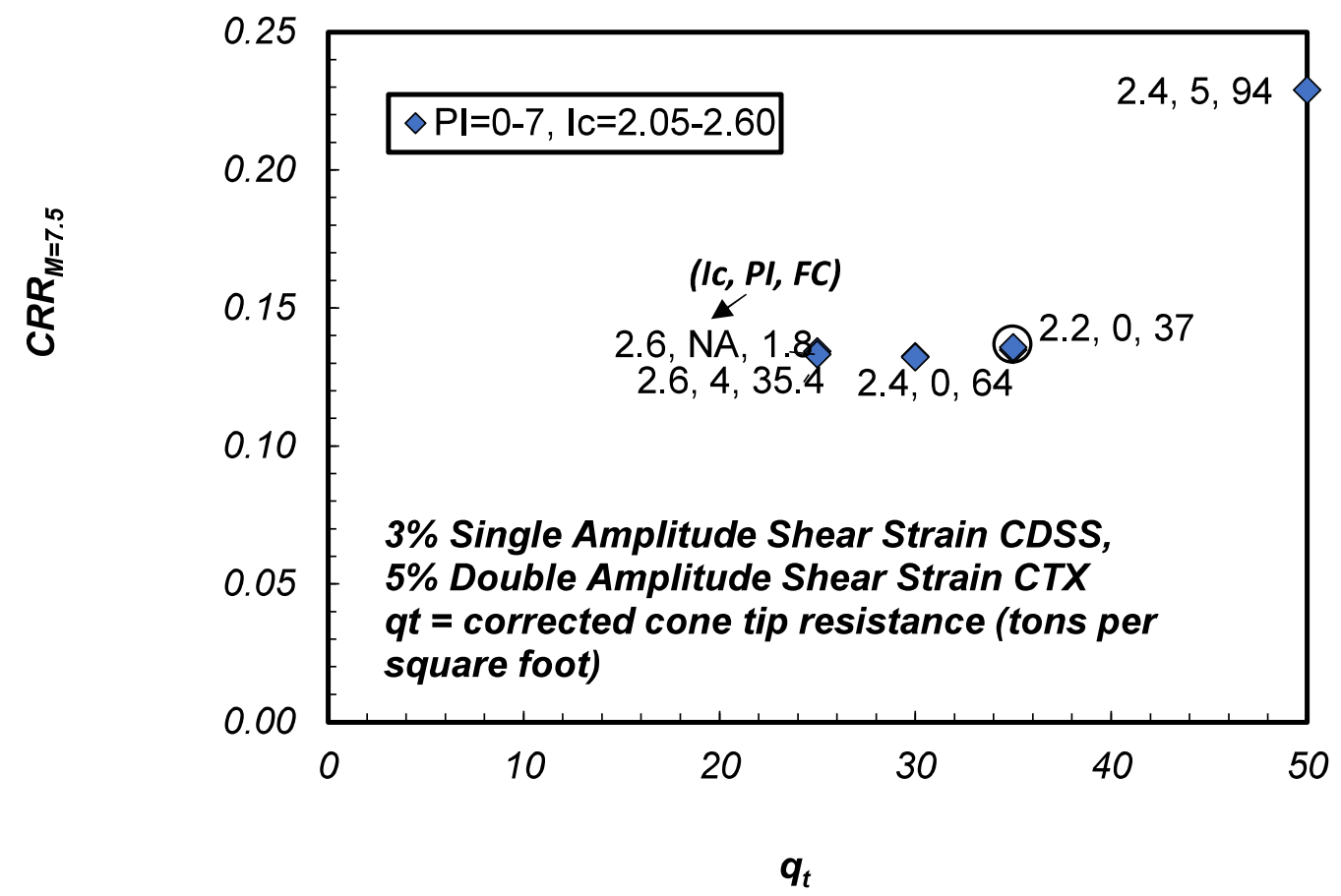

Figure 17. Corrected $q_{c}$ data plotted against CRR and categorized by Ic (2.05-2.60) and PI (0-7), with FC as a supplement.

Figure 17 shows data categorized with PI less than or equal to 7 and Ic ranging from 2.05 to 2.60. The CRR remains approximately 0.14 for tip resistance values from 25 to 35 tsf and increases to approximately 0.23 with a tip resistance of $50 \mathrm{tsf}$. This plot may indicate that some relationship exists for CRR of sand like material and $\mathrm{q}_{\mathrm{t}}$, but more data points would be needed for further evaluation outside the scope of this research.

Figure 18 shows data categorized with PI greater than 7 and Ic greater than 2.6. The CRR ranged from 0.125 to 0.37 . The plotted data based on $\mathrm{PI}$ and Ic is identical to the $\mathrm{PI}>7$ data from Figure 12 owing to all points with $\mathrm{PI}>7$ having Ic greater than 2.6. This 
observation indicates that the CPT parameters assigned to each sample have Ic values that agree with the laboratory PI results for clay-like behavior from Idriss and Boulanger (2006).

The data presented in Figure 18 do not show a strong $\mathrm{q}_{\mathrm{t}}-\mathrm{CRR}$ relationship. This may be due to insufficient data points; the $\mathrm{q}_{\mathrm{t}}$-CRR relationship for soil behavior type not being strong; or the estimated CPT data was not representative of sampled soil.

Figure 19 shows data which has Ic and PI outside the bounds of the above criteria for Figures 17 and 18 . The CRR ranged from 0.15 to 0.24 , and tip resistance values ranging from 5 to 40 tsf. The sample data included in the plot may have Ic values greater or less than 2.6 but possess PI values less than or greater than 7, respectively.

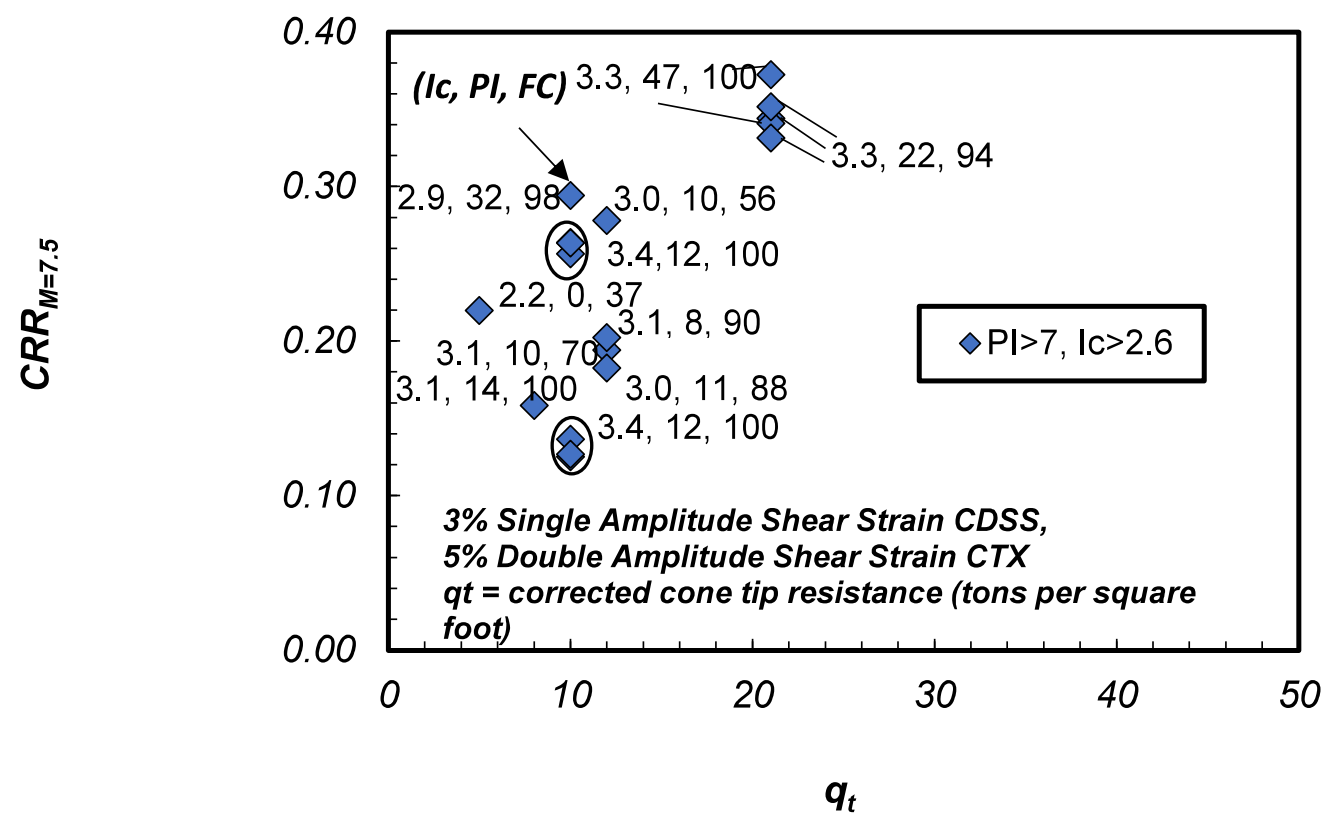

Figure 18. Corrected $\mathrm{q}_{\mathrm{c}}$ data plotted against CRR and categorized by Ic (greater than 2.6) and PI (greater than 7) with FC as a supplement. 


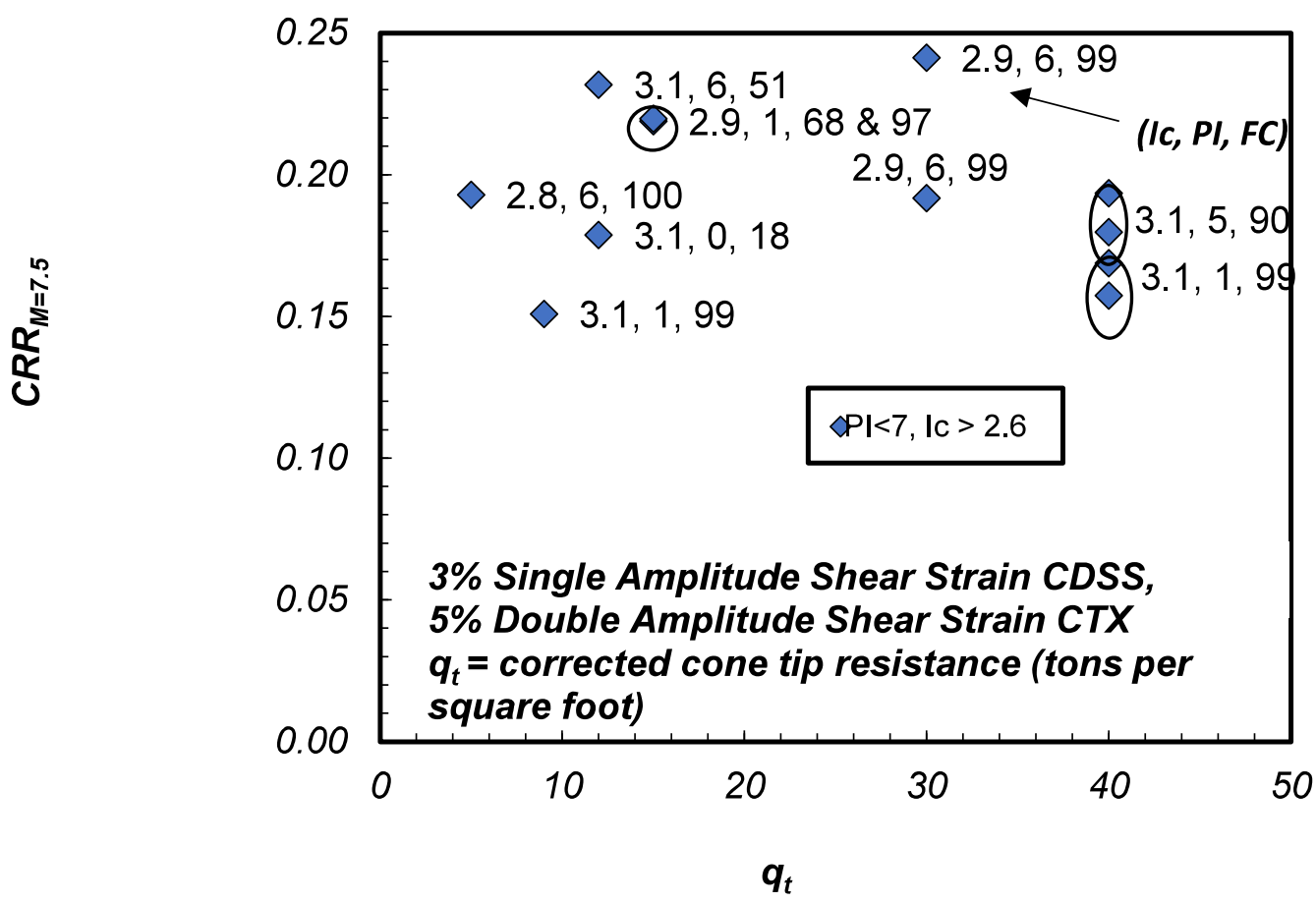

Figure 19. Corrected $\mathrm{q}_{\mathrm{c}}$ data plotted against CRR and categorized by Ic (greater than 2.6) and PI (less than 7)

The data from Figure 19 shows that while the Ic values may be greater than 2.6 for all samples, the PIs are less than 7 except for one data point. This observation suggests that a sample may have a PI indicating that the material is sand-like and susceptible to liquefaction, but the Ic values indicate that the material is clay-like and not susceptible to liquefaction.

The normalized cone tip resistance data was categorized using the same methods outlined in the previous $\mathrm{q}_{\mathrm{t}}$ CRR section. As seen in Figure 20, normalization of the data caused shifts in the data that allowed for some trend observations to be made. Ic values 
ranging from 2.05 to 2.6 have $q_{\mathrm{c} 1 \mathrm{~N}}$ ranging from 12 to 49 , with CRR ranging from 0.13 to 0.23. These data lie closely to the plotted Idriss and Boulanger (2014) line with a FC of 70. Ic values ranging from 2.6 to 3.6 cluster at tip resistance values ranging from 7 to 24 , with corresponding CRR ranging from approximately 0.13 to 0.37 . Except for the 4 data points clustered at $\mathrm{q}_{\mathrm{c} 1 \mathrm{~N}}$ ranging from 22 to 24 with Ic of 3.1, the data generally shows increasing CRR with increasing IC.

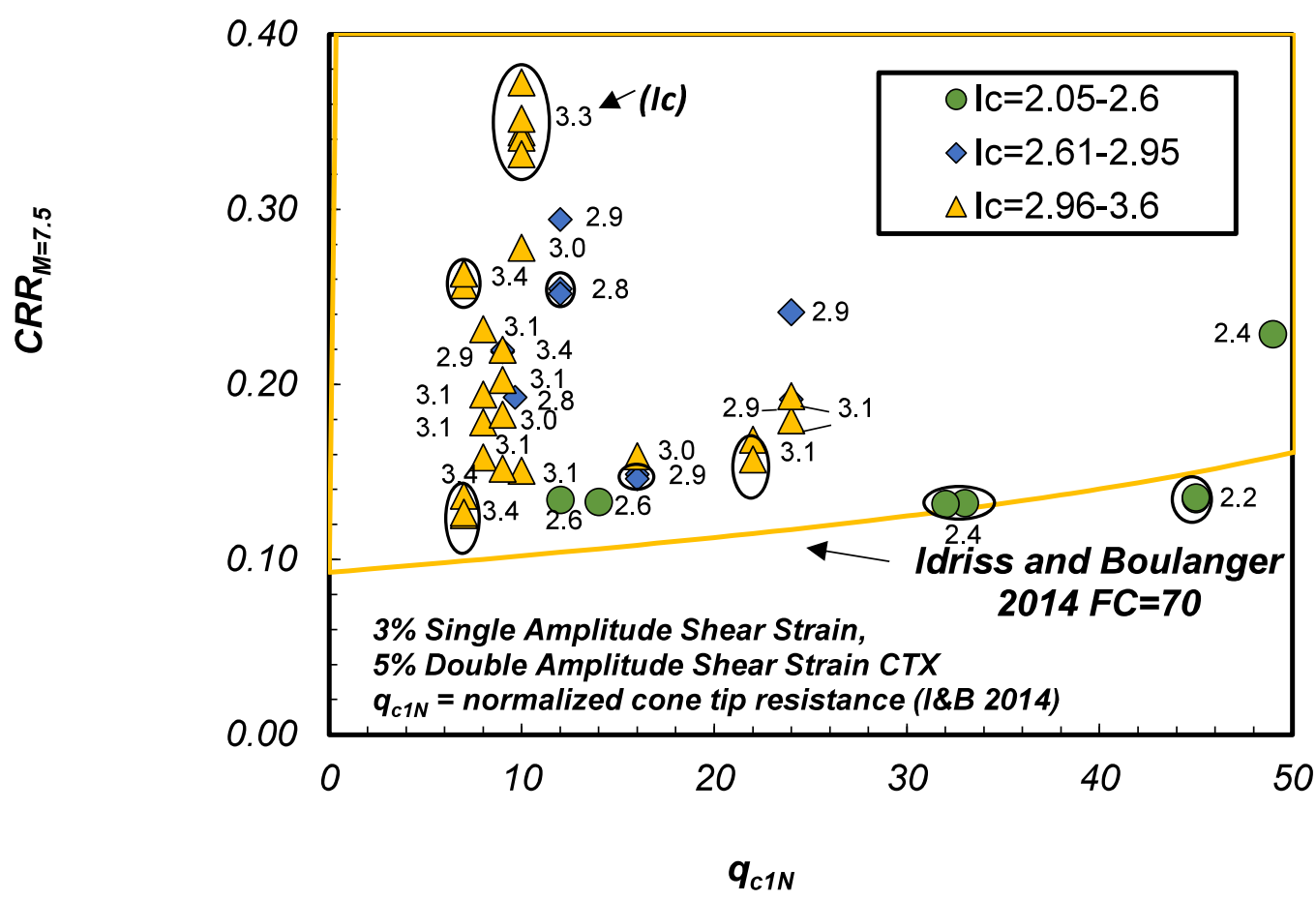

Figure 20. Normalized $q_{c}$ data plotted against CRR and categorized by Ic.

Similarly, to the Figure 13 for $\mathrm{qt}_{\mathrm{t}}$-CRR sand-like behavior, CRR remains approximately 0.13 over a certain range of tip resistance values. However, normalization of the data created a spread and the normalized tip resistance values range from 12 to 45 across an approximate CRR of 0.13 . As observed in Figure 13 this plot may indicate that some 
relationship exists for CRR of sand like material and normalized cone-tip resistance, but more data points would be needed for further evaluation outside the scope of this research.

Figure 21 shows tip resistance data categorized with Ic greater than 2.6 and PI greater than 7. Generally, for the range of tip resistances plotted in Figure 21, the tip resistance values increase with increasing CRR. To attempt to further characterize this relationship, the CRR for clay-like material from Idriss and Boulanger (2008) was plotted along with the sample data and compared with Price et al. (2015).

Assumptions were necessary for the input values required to use the equation CRR for clay-like material from Idriss and Boulanger (2008) where CRR is approximately $0.8^{*} \mathrm{~S}_{\mathrm{u}} / \sigma^{\prime}{ }_{\mathrm{vc}}$ and $s_{u}$ is the undrained shear strength. The total stress for each point on the line was assumed at $2 \mathrm{~atm}$ (approximately $200 \mathrm{kPa}$ ) and the effective stress was assumed at $1 \mathrm{~atm}$ (approximately $100 \mathrm{kPa}$ ). Non-normalized tip resistance values were used to calculate the $S_{u}$ with a cone factor $\left(N_{k t}\right)$ of 15 which is consistent with the value used in Price et al. (2015): 


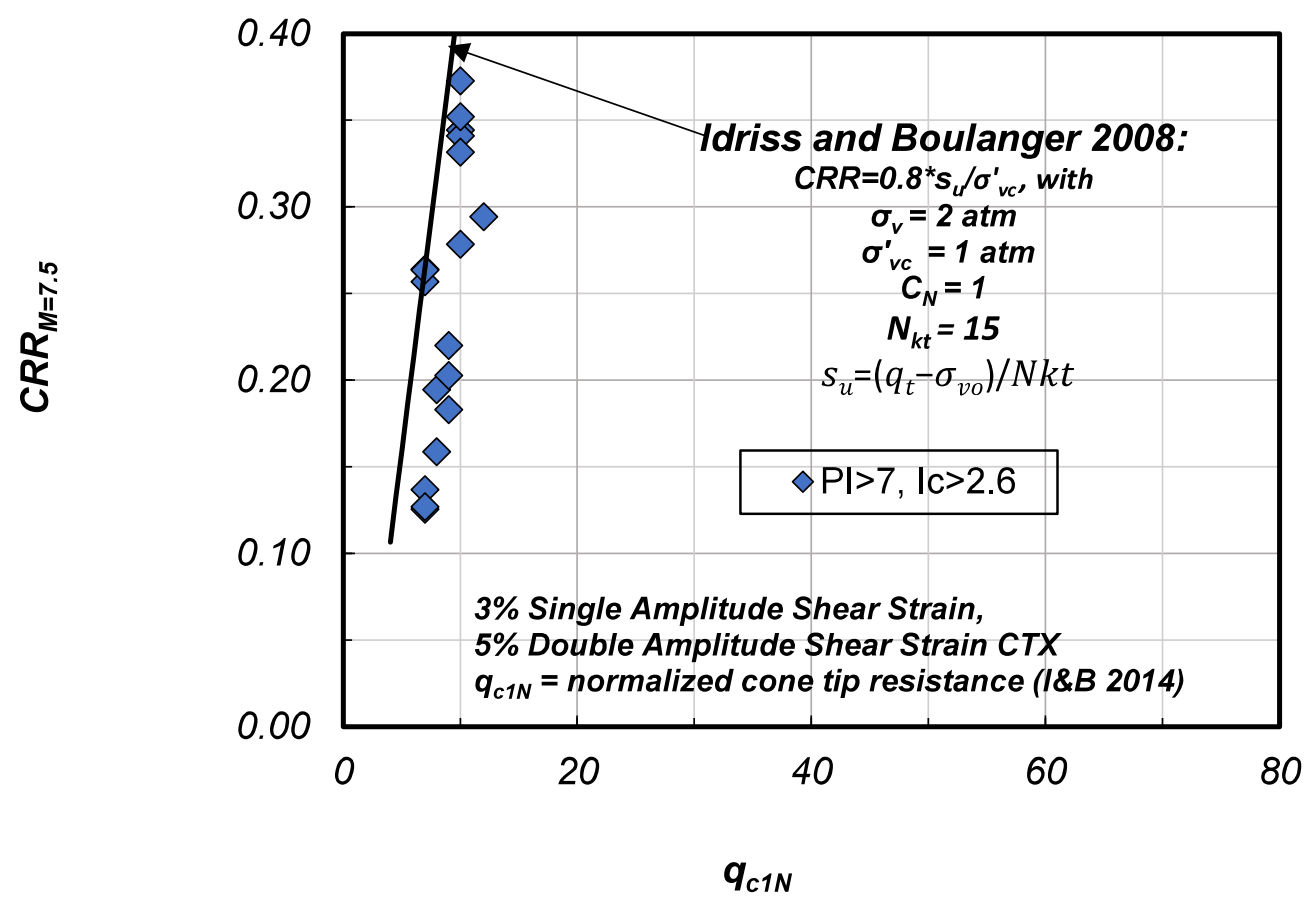

Figure 21. Normalized $q_{c}$ data plotted against CRR and categorized by Ic (greater than 2.6), and $\mathrm{PI}$ (greater than 7).

The equation from Idriss and Boulanger (2014) used to calculate $q_{c 1 N}$ is $q_{c 1 N}=C_{N} *\left(q_{c} / P_{a}\right)$. Atmospheric pressure, $\mathrm{P}_{\mathrm{a}}$, is roughly equivalent to 1 tsf, the same units used for corrected cone tip resistance $q_{t}$. With the overburden and effective stress equal to 2 tsf ( 2 atm) and $1 \mathrm{tsf}(2 \mathrm{~atm})$, the calculated overburden correction factor $C_{N}$ was equal to 1 . Therefore, the $\mathrm{q}_{\mathrm{c}}-\mathrm{x}$-axis values shown in Figure 22 is equal the $\mathrm{q}_{\mathrm{c} 1 \mathrm{~N}} \mathrm{X}$-axis values shown in Figure 21 .

The CRR data from Price et al. (2015) were determined from laboratory CDSS tests and the $\mathrm{q}_{\mathrm{c}}$ data were obtained from CPT simulations. The CPT data from this research was then plotted on Figure 22. The sample data and in-situ data from this research with PI greater than 7 and Ic greater than 2.6 agrees with the $q_{c}-C R R$ relationship for shaded regions of $\mathrm{PI}=6$ and 20 shown by Price et al (2015). 


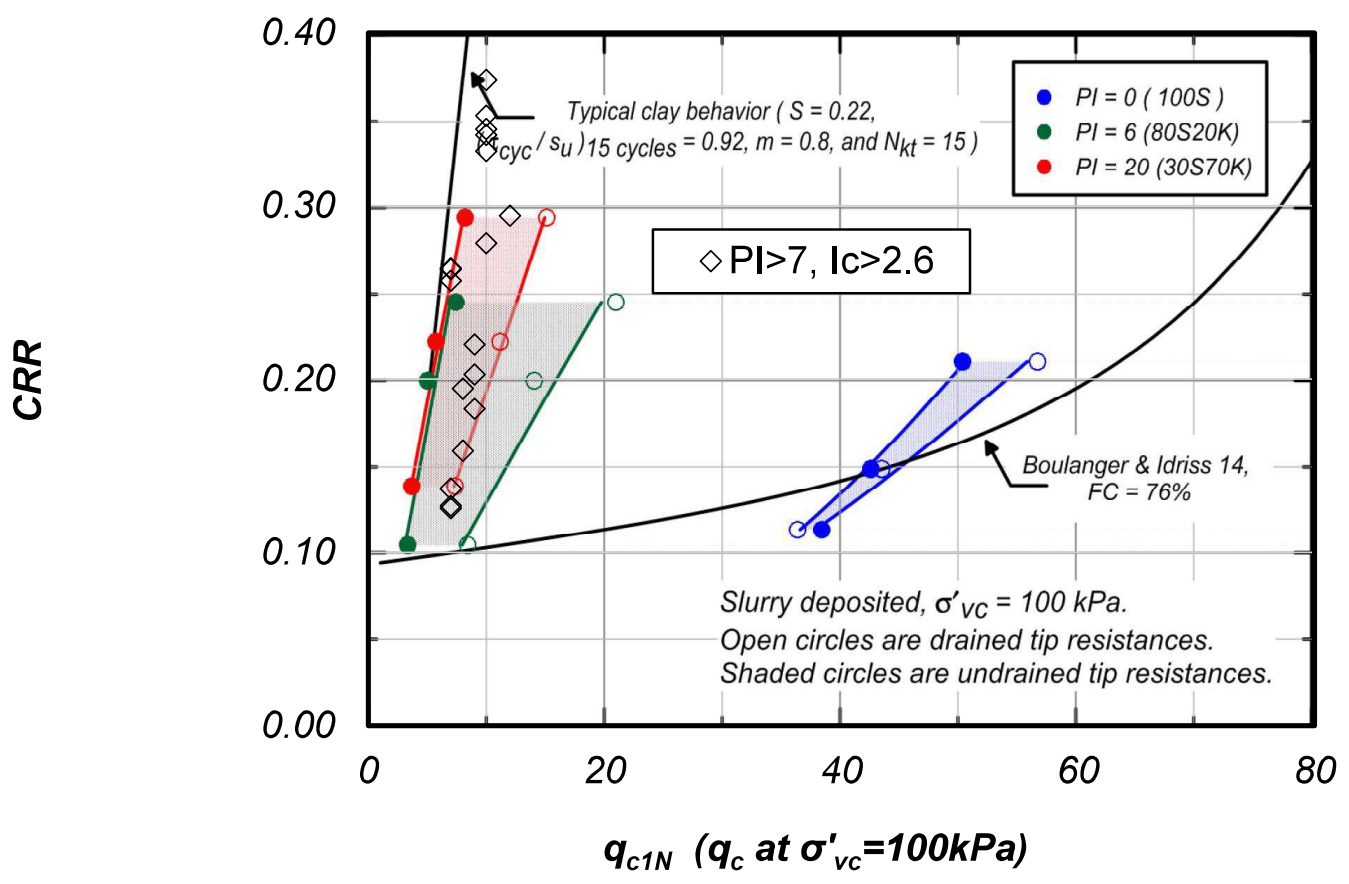

Figure 22. Normalized $q_{c}$ data plotted against CRR and categorized by PI (greater than 7).Original figure data $\mathrm{q}_{\mathrm{c}}-\mathrm{CRR}$ relationships for intermediate soils from Price et al. (2015)

Figure 23 shows data categorized with Ic 2.6 or less and PI ranging from 0 to 7. CRR ranged from 0.13 to 0.23 , and $q_{\mathrm{c} 1 \mathrm{~N}}$ ranged from 12 to 49 . Data from tip resistances of 12 to 45 fall relatively close to and above the Idriss and Boulanger (2014) line for FC of 70. The higher CRR of the data point with tip resistance of 49 may owe to either the higher PI of 5, or the larger FC of 94 relative to the other samples.

Figure 24 shows data categorized by PI less than 7 and Ic greater than 2.6. The CRR ranged from 0.15 to 0.24 , and $q_{\mathrm{c} 1 \mathrm{~N}}$ ranging from 8 to 24 , which is a much more narrow range compared to the non-normalized data 5 to 40 tsf observed in the $\mathrm{q}_{\mathrm{t}}-\mathrm{CRR}$ section for this 
same criteria. This observation shows that normalization of the data had a much more significant effect on the tip resistance CRR plot and made possible trends more apparent.

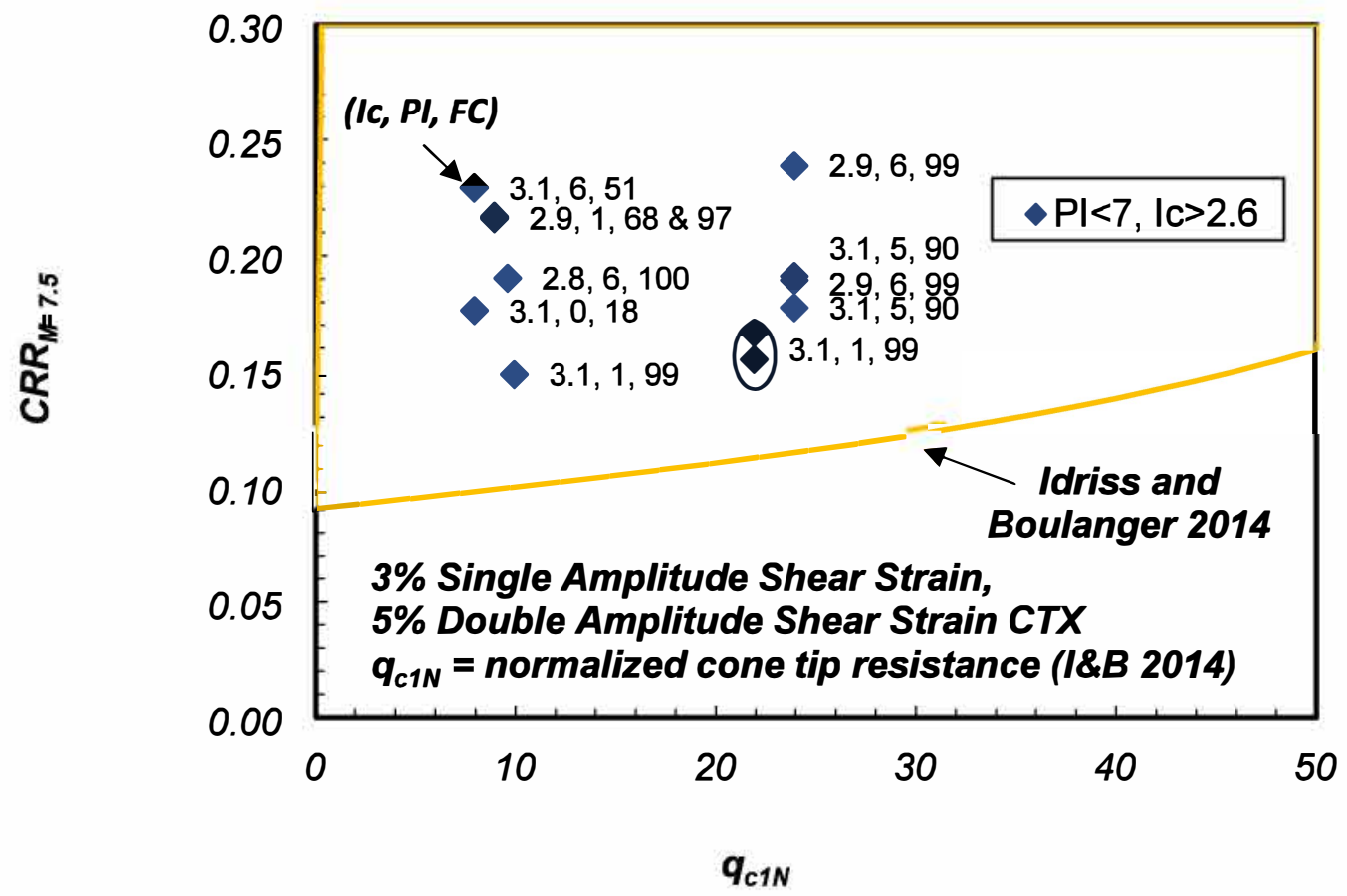

Figure 23. Normalized cone tip resistance data plotted against CRR and categorized by IC (greater than 2.6) and PI (less than7).

Figure 24 shows $\mathrm{q}_{\mathrm{c} 1 \mathrm{Ncs}}$ data are shown in Figure 22 , where Ic is 2.6 or less, and PI ranges from 0-7. The purpose of further analyzing these data is to evaluate the sand-like behavior categorized by Idriss and Boulanger (2006) and Robertson (2009) with PI and Ic. Figure 24 shows the equivalent clean sand tip resistance data categorized by Ic and PI. Generally, CRR increases with increasing tip resistance. The $\Delta \mathrm{q}_{\mathrm{c} 1 \mathrm{~N}}$ values added the data shown in Figure 24 caused the points to shift to the right from the $q_{\mathrm{c} 1 \mathrm{~N}}$ plot, closer to the Idriss and Boulanger (2014) line. The most significant shift in the data is observed in the data point 
with a normalized tip resistance of 49 , where the $\mathrm{FC}$ of 94 meant that the equivalent clean sand value is $118\left(\Delta \mathrm{q}_{\mathrm{c} 1 \mathrm{~N}}=79\right)$.

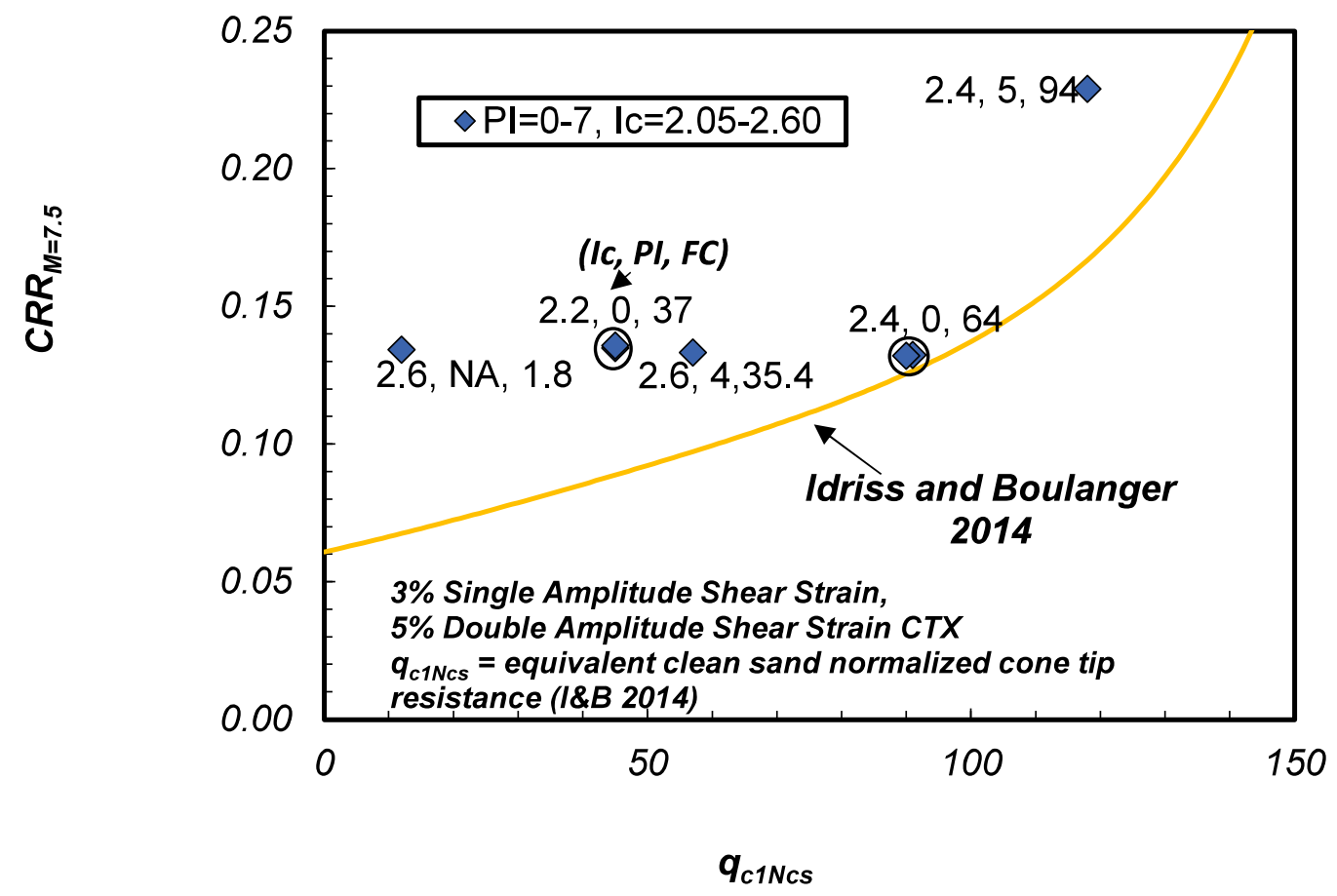

Figure 24. Equivalent clean sand normalized $\mathrm{q}_{\mathrm{c}}$ resistance data plotted against CRR and categorized by Ic and PI. 
Role of OCR in $\mathrm{q}_{\mathrm{c}}$-CRR Relationships

The effect of over-consolidation ratio is known to have a direct effect on the strength of soils, as observed in the SHANSEP relationship as discussed Briaud (2013). OCR effects on $\mathrm{q}_{\mathrm{c}}$-CRR relationships was briefly analyzed in this research. OCR for samples in this research was categorized based on the laboratory-induced OCR within the ranges of OCR equal to 1 and OCR greater than 1 as seen in Figure 25. In general, increase in OCR seems to correspond to an increase in CRR. Samples with OCR of 1 have CRR values ranging from of 0.13 to 0.28 . Samples with OCR greater than 1 have CRR values ranging from 0.18 to 0.37 .

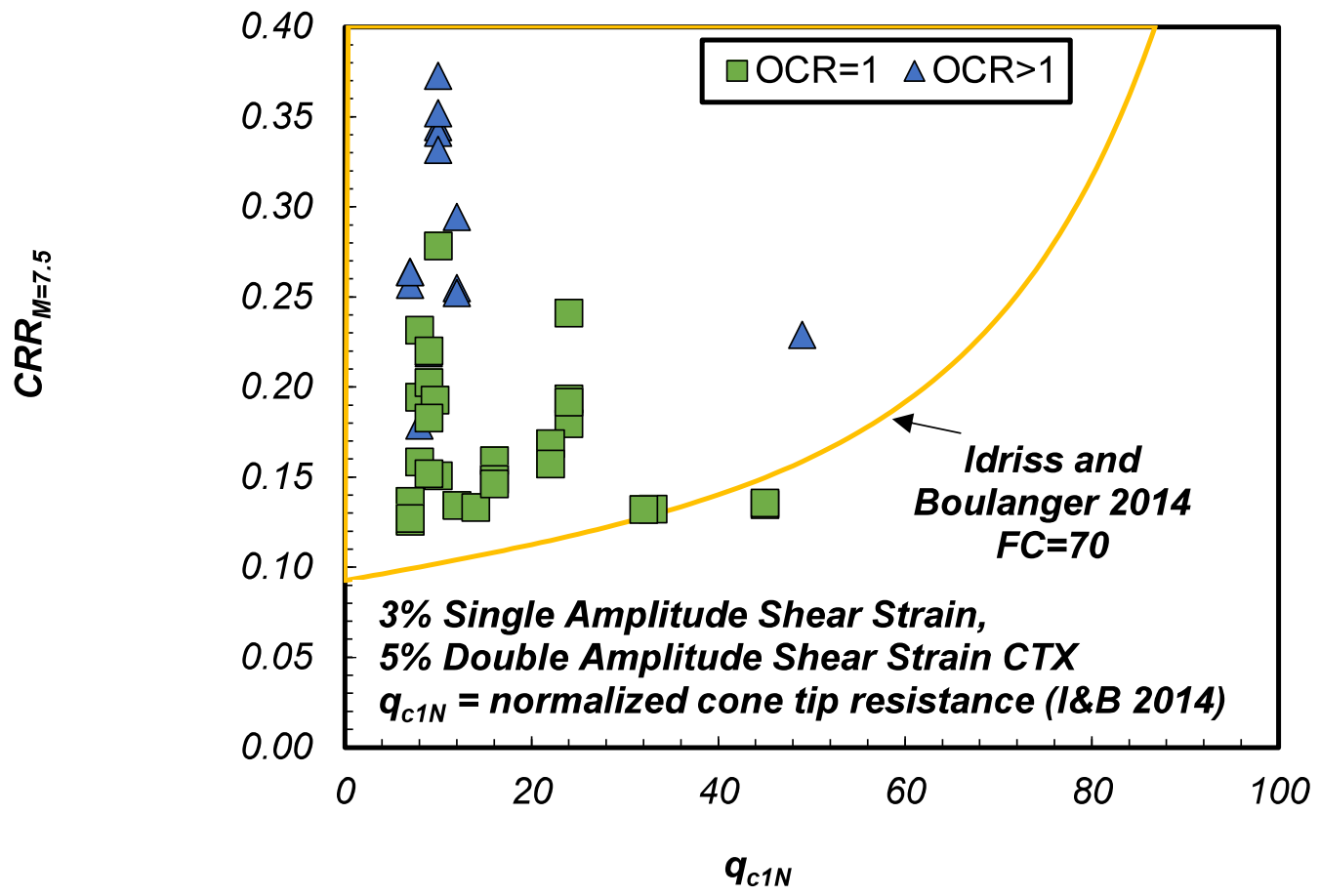

Figure 25. Normalized cone tip resistance plotted against CRR categorized by OCR. 
SPT-CRR

SPT-measured $\mathrm{N}$ values and N160 values were compared against the laboratory determined CRR. As previously mentioned, the SPT data was not the focus of this research. Therefore, the following SPT and Vs Figures and discussions are not as extensive as the previous CPT sections.

Figure 25 shows a plot of field SPT N-values versus laboratory CRR. SPT values range from 0 to 21 , with corresponding CRR ranging from 0.13 to 0.29 .

Figure 26 shows a plot of normalized $\left(\mathrm{N}_{1}\right)_{60}$ data plotted against laboratory CRR including the deterministic CRR line with FC of70 from Idriss and Boulanger 2014. $\left(N_{1}\right)_{60}$ values range from 0 to 34, indicating that the normalization of the field SPT data increased the range of SPT values. Figure 27 shows a plot of equivalent clean sand normalized $\left(\mathrm{N}_{1}\right)_{60 \mathrm{cs}}$ values versus laboratory CRR. $\left(N_{1}\right)_{60 \text { cs }}$ values ranged from 6 to 40 , which indicates that the range from Figure 27 was shifted 6 points to the right due to the FC of those samples. Like Figures 26 and 27, the CRR slightly increases with increasing $\left(N_{1}\right)_{60 c s}$ values. However, some of this data may be erroneous since the clean sand correction only applies to sandlike behaving materials which is not likely the case for all data points. Further evaluation of these data is outside the scope of this dissertation. 
$\frac{n}{0}$

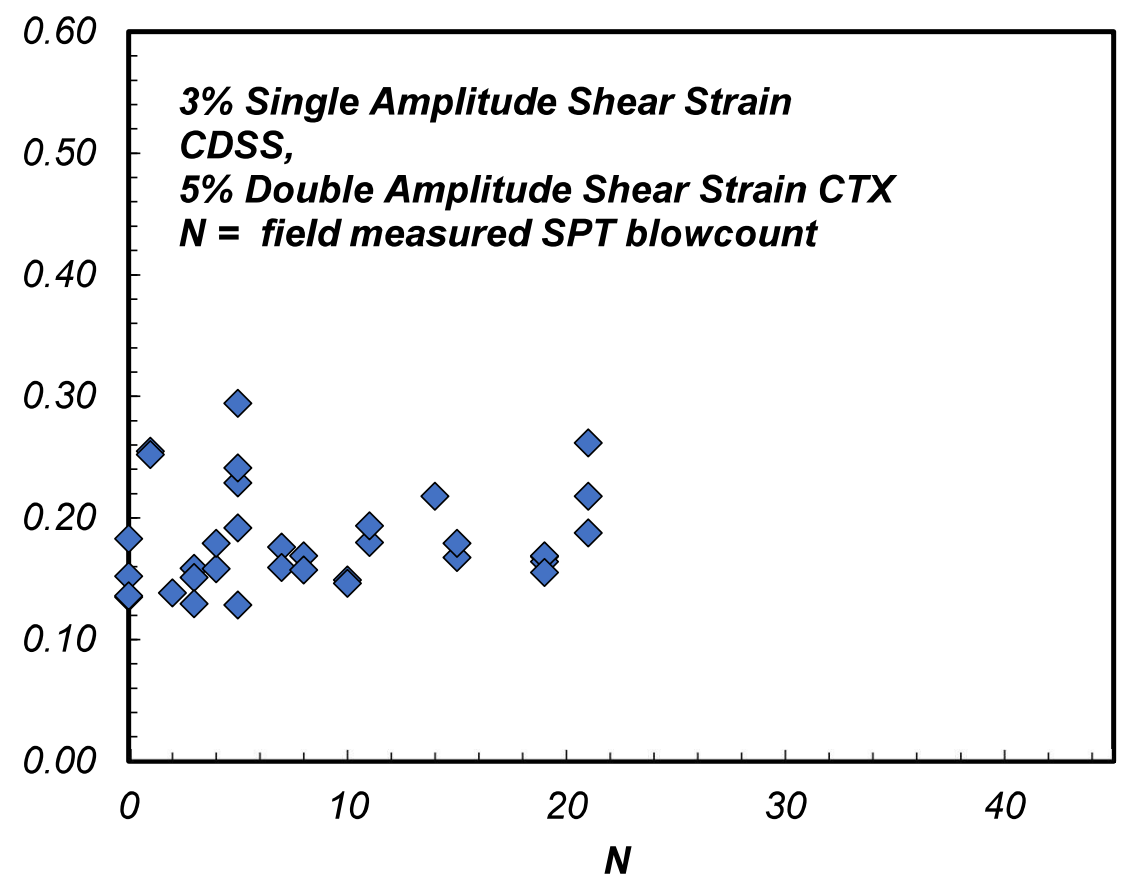

Figure 26. Field SPT N values plotted against CRR

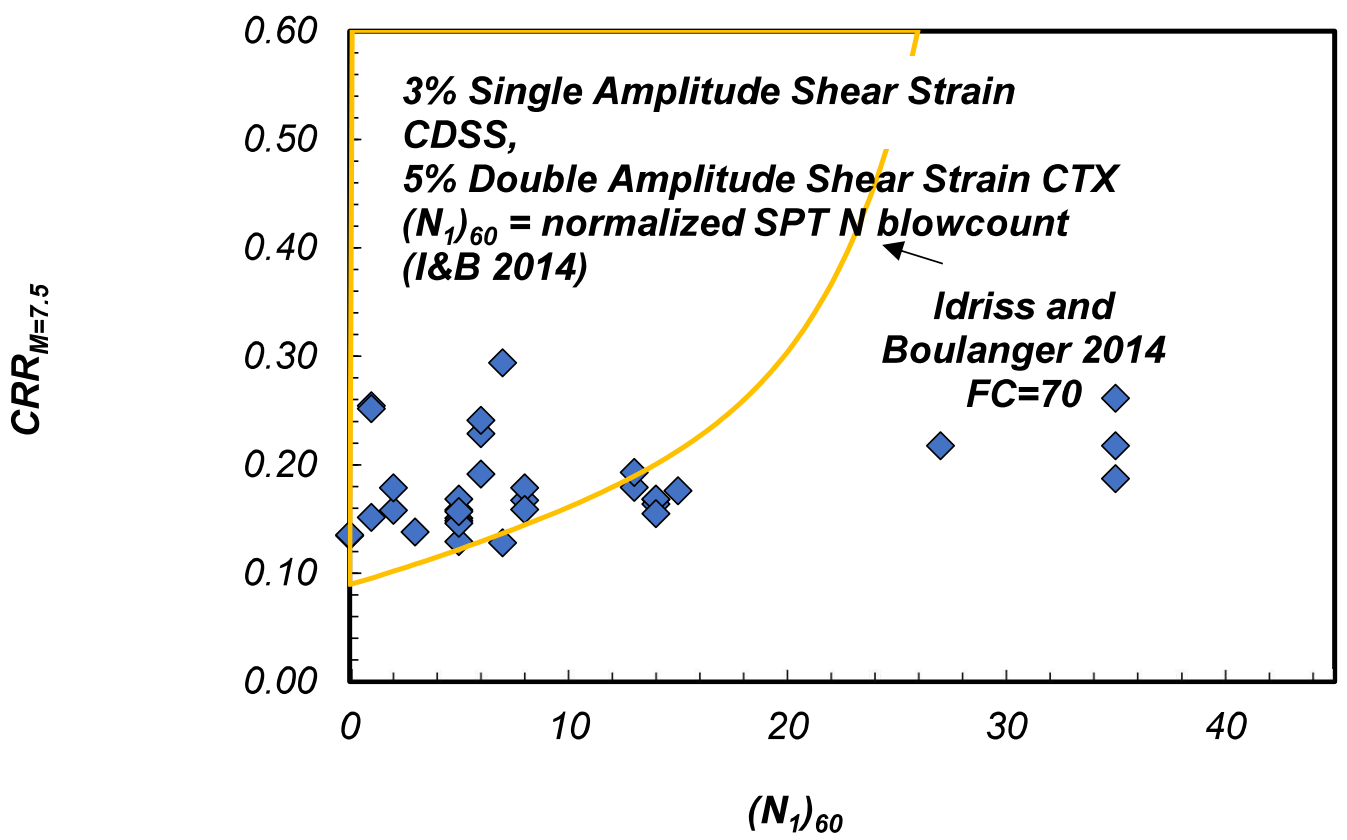

Figure 27. Normalized SPT $\left(N_{1}\right)_{60}$ values plotted against CRR. 


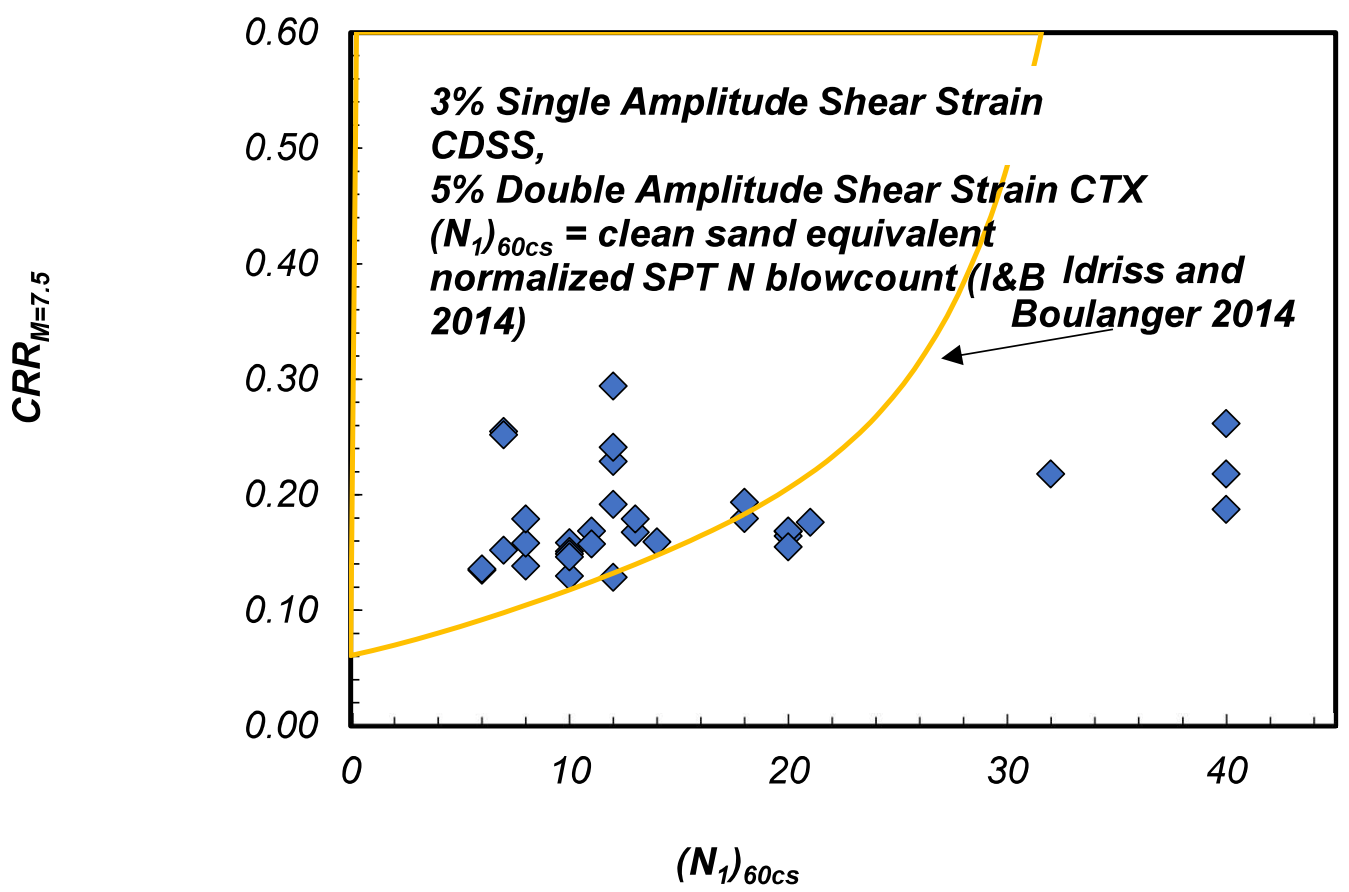

Figure 28. Equivalent clean sand normalized SPT $\left(\mathrm{N}_{1}\right)_{60 c s}$ data plotted against CRR. 
$\mathrm{V}_{\mathrm{s}}-\mathrm{CRR}$

Measured field shear wave velocity, $V_{s}$, were used alongside the normalized shear wave velocity, $\mathrm{V}_{\mathrm{s} 1}$, to compare against laboratory determined CRR. Shear wave velocity data for each cyclic sample was limited by the limited number of in-situ tests performed, and there are notably fewer data points when compared to the SPT and CPT data. As shown in Figure 29, measured shear wave velocity for the cyclic samples ranges from 367 to 890 feet per second, with corresponding CRRs ranging from 0.16 to 0.29 . No apparent trend is visible for this data set.

Normalized shear wave velocity $V_{s 1}$ was plotted using the Figure from Dobri and Andoun (2015) to compare against laboratory CRR and can be seen in Figure 30 . The $V_{s 1}$ values range from 337 to 893 , with corresponding CRR ranging from 0.16 to 0.29 . The data plot to the left of the line proposed in Figure 30 except for one data point. Further evaluation of this data is needed to determine any trend in CRR with $\mathrm{V}_{\mathrm{s} 1}$ based on $\mathrm{PI}, \mathrm{FC}$, or Ic. 


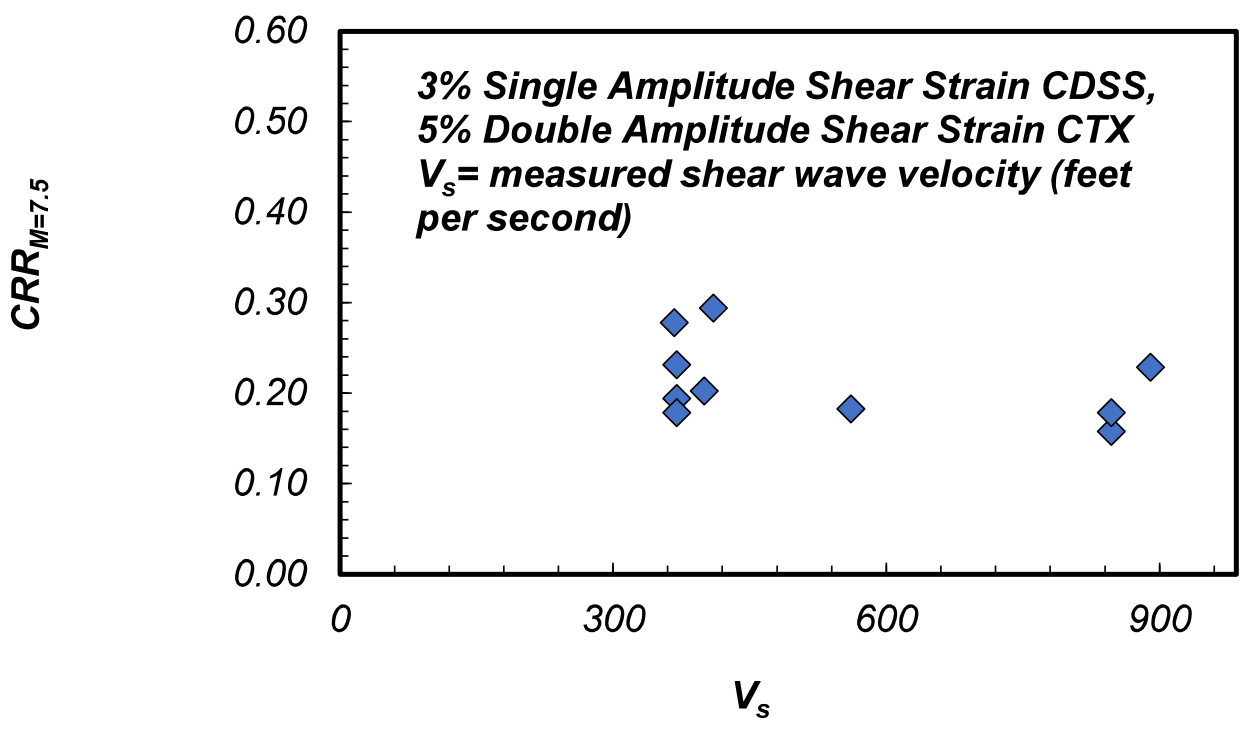

Figure 29. Shear Wave velocity, Vs, data plotted against CRR. 


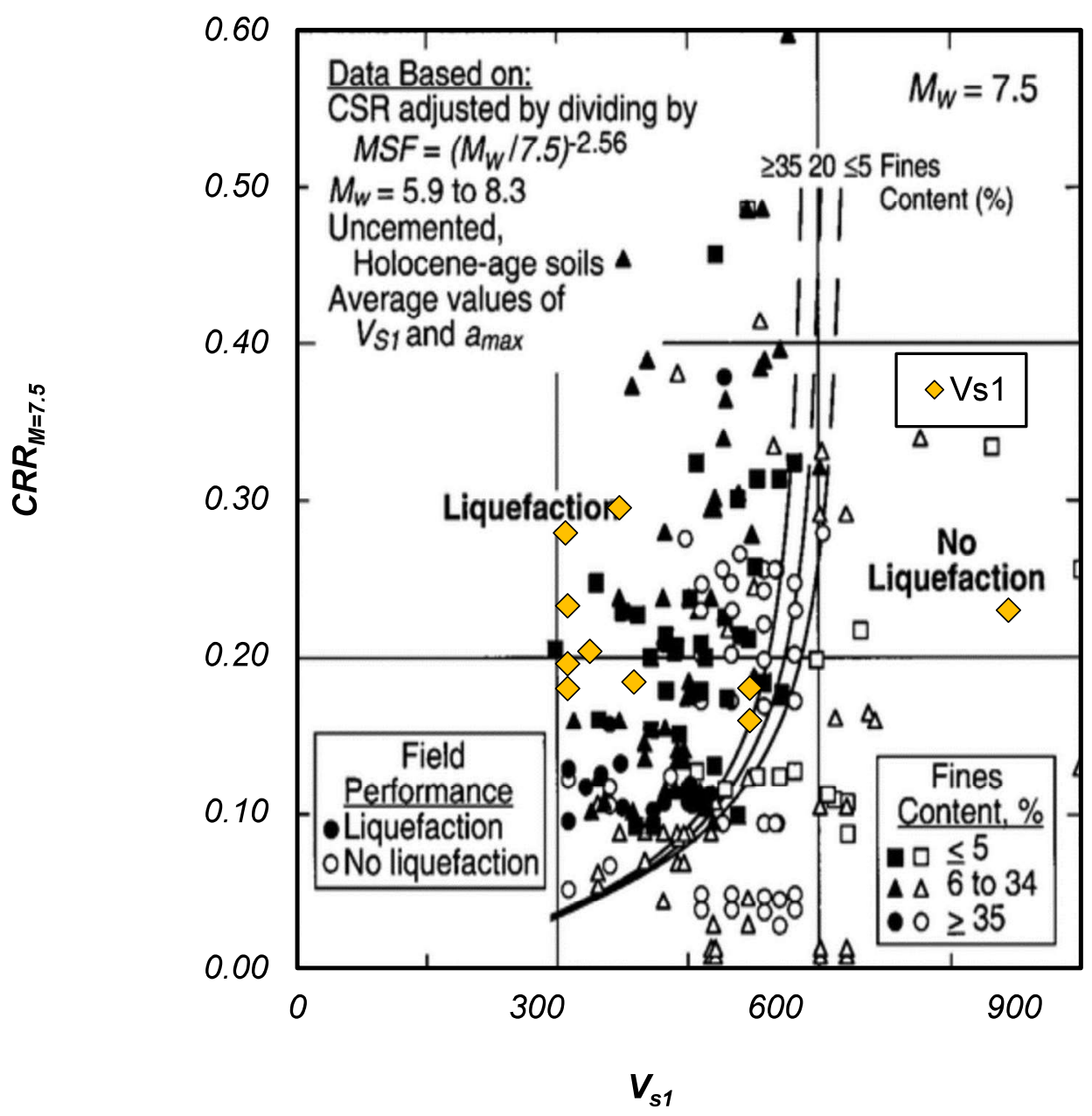

3\% Single Amplitude Shear Strain CDSS, 5\% Double Amplitude Shear Strain CTX

$V_{s 1}=$ normalized shear wave velocity (feet per second)

Figure from Dobri and Andoun (2015)

Figure 30. Normalized shear wave velocity, $\mathrm{V}_{s 1}$, data plotted against CRR. 


\section{Summary and Conclusions}

In-situ test measurements of silty soils were extracted from project sites in Oregon and Washington. These in-situ test types included, CPT, SPT, and shear wave velocity. The focus of this research was on the CPT for its relevance in liquefaction triggering and reliability. Laboratory CRR data obtained from the silty soils database provided by New Albion Geotechnical in collaboration with Portland State University was used to compare with in-situ test data. CPT data was screened with FC, PI, and Ic data where applicable. These data were processed using Idriss and Boulanger (2008\&2014) liquefaction triggering methods for both sand and clay-like soils. SPT and shear wave velocity was not screened with FC, PI, Ic, as these methods were not the focus of this research. However, these results will likely be addressed in future research.

The role of FC was observed to not have a clear relationship with CRR for the analyzed

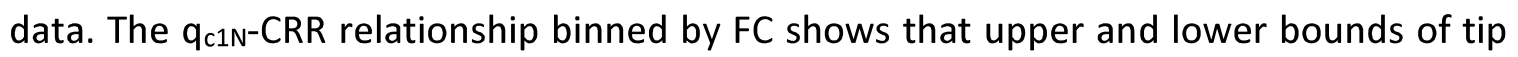
resistances contain FC of all ranges. This is the similar case to CRR with FC, however the highest CRR values from 0.27 to 0.37 have FC ranging from 91-100. Additional difficulties in analyzing the effects of FC with CRR in this research owes to the variability of soil properties over short distances. For example, project 0-07 .had three CDSS samples taken from a Shelby tube with corresponding FC of 18,51 , and 70 . The measured cone tip resistance for these samples was $12 \mathrm{tsf}$, and corresponding $\mathrm{q}_{\mathrm{c} 1 \mathrm{~N}}$ values were equal to 8 . The CRRs for FC of 18,51 , and 70 were $0.18,0.23$, and 0.20 respectively. 
The role of plasticity index was observed to have an apparent effect on $\mathrm{q}_{\mathrm{c}}-\mathrm{CRR}$ relationships for silty soils. Soils, with PI greater than 7 showed trends consistent Idriss and Boulanger (2008) cyclic softening behavior. These results are over a relatively small and narrow range of cone tip resistance data, and future research may need to analyze samples with higher cone tip resistances and CRR to further establish the relationship. The relationship with cone tip resistance and CRR for PI less than or equal to7 are not apparent. This may be due to selective bias in the data, where critical soil layers with low $\mathrm{q}_{\mathrm{t}}$ values were targeted for sampling and testing. Therefore, there are few datapoints at higher $\mathrm{q}_{\mathrm{c}}$ values where increases in CRR would be observed. Future research may address this issue.

The role of soil behavior type was observed to identify trends in CRR between Ic values from 2.05 to $2.6,2.6$ to 2.95 , and 2.95 to $3.4 \mathrm{q}_{\mathrm{c} 1 \mathrm{~N}}-\mathrm{CRR}$ data. With Ic values from 2.05 to 2.6, increasing tip resistance values corresponds to a relatively low increase in CRR and remains relatively constant at approximately 0.13 The upper and lower bounds of CRR for Ic 2.6 or less are. 0.140 .23 with corresponding $q_{\mathrm{c} 1 \mathrm{~N}}$ values from 12 to 49 . For Ic greater than 2.6, CRR values were larger over a narrower range of $\mathrm{q}_{\mathrm{c} 1 \mathrm{~N}}$. The upper and lower bounds of CRR are 0.13 to 0.37 , with corresponding $q_{\mathrm{c} 1 \mathrm{~N}}$ values ranging from 7 to 24 . Ic greater than 2.6 was screened at ranges of $2.6-2.95$, and 2.96 and greater, but the data do not show sensitivity with these Ic ranges and CRR. Therefore, sensitivity was observed between Ic vales of 2.6 and greater and Ic values greater than 2.6. 
Ic with PI was also analyzed to identify any possible trends between $\mathrm{q}_{\mathrm{c}}-\mathrm{CRR}$. Three separate screening criteria were used to identify any sensitivity. These were Ic of 2.6 or less with PI less than or equal to 7, Ic greater than 2.6 with PI greater than 7, and soils which fall into either or neither of these categories. Data with Ic of 2.6 or less and PI of 7 or less were observed to have relatively low CRR over a relatively wide range of tip resistance. This criterion was both analyzed with $\mathrm{q}_{\mathrm{c} 1 \mathrm{~N}}$ and $\mathrm{q}_{\mathrm{c} 1 \mathrm{Ncs}}$ cone tip resistance values. In both cases, the tip resistance and corresponding CRR plotted close the Idriss and Boulanger (2014) relationships, with CRR not exceeding 0.23

All data with PI greater than 7 also had Ic greater than 2.6, therefore the previously discussed relationship that was compared with Price et al (2015) also applies to the role of Ic and PI. Ic values greater than 2.6 however did not correspond to PI greater than 7 in all cases, as seen in the data categorized by Ic greater than 2.6 and PI less than 7 . This observation suggests that data PI greater than 7 better represents clay-like behavior than Ic values greater than 2.6. This observation is consistent with Idriss and Boulanger (2006) that states PI at 7 or greater indicates clay-like behavior.

The data which fall into neither of these categories do not qualify as sand-like or clay-like as defined by both Idriss and Boulanger (2014) and Robertson (2009). These data mostly had Ic values greater than 2.6 but PIs less than 7 . The Ic data greater than 2.6 would suggest that the soil is behaving more clay-like based on the CPT (Robertson 2009), while the PI from lab index testing would suggest that the soil is behaving more sand-like (Idriss 
and Boulanger 2006). Further research into these soils that do not fall into either clay-like or sand-like may reveal relationships between $\mathrm{q}_{c}$ and CRR. The importance of the data in these ranges lies in the fact that the cyclic behavior of these soils is difficult to predict with current in-situ triggering methods, and future research is needed to identify any potential relationship between $q_{c}$ and CRR.

The suggested soil types of sand-like, clay-like, and transitional were defined based on the observations made when soil was categorized with having Ic of 2.6 or less and PI of 7 or less (sand-like), having Ic greater than 2.6 and PI greater than 7 (clay-like), and soils that had Ic greater than 2.6 and PI less than 7 (transitional). The soil types which fall into these categories were plotted in Figure 30. In addition to this criteria, the estimate ranges of potential $\mathrm{q}_{\mathrm{c}}$ values were plotted to illustrate the uncertainty in assigning in-situ data points to cyclic sample data. 


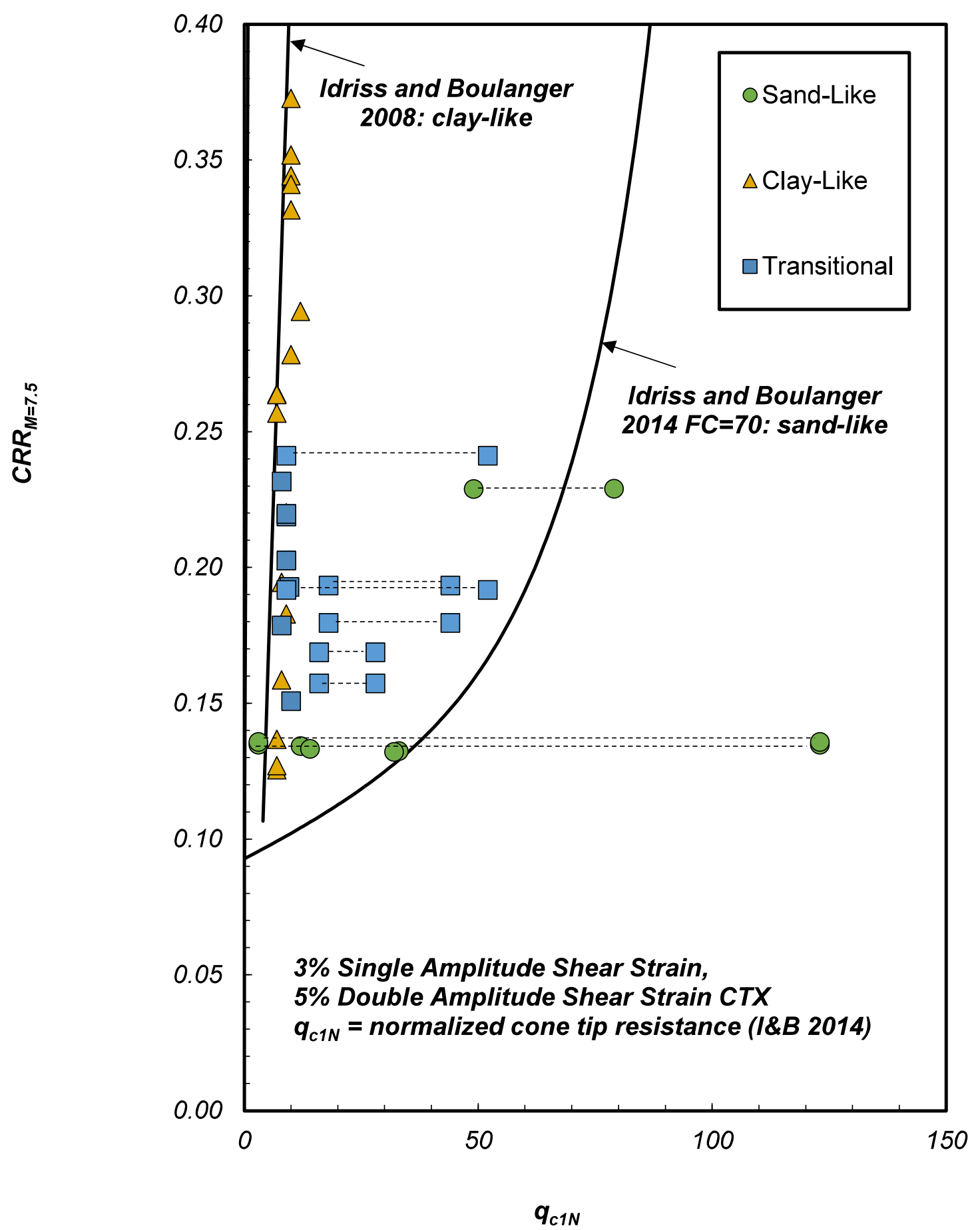

Figure $31 . q_{\mathrm{c} 1 \mathrm{~N}}-\mathrm{CRR}$ relationships for silty soils in the pacific northwest. 
In Figure 31, the relationships for sand-like and clay-like behavior were represented by Idriss and Boulanger (2014) FC=70 line, and Idriss and Boulanger (2008) clay-like CRR relationships previously analyzed, respectively. The transitional data identified herein plot within the clay-like and sand-like relationship plotted from Idriss and Boulanger (2014) and (2008), respectively. This observation is in agreement with the assumption that transitional soils lie in between sand-like and clay-like behavior. With the plotted ranges of $\mathrm{q}_{\mathrm{c} 1 \mathrm{~N}}$, represented by two data points for each upper and lower bound point connected by a dashed line. The data showed some variability but still plotted within the expected ranges for their corresponding soil type. For project $W-09$, the range of $q_{c 1 N}$ data for CRR of 0.135 and 0.136 were 3 to 123 . This wide ranges of data suggests that the $q_{c}-C R R$ for these samples is difficult to estimate due to the wide range of $q_{c 1 N}$ due to the likelihood of over-predicting or under-predicting the CRR based on in-situ data.

Based on Figure 31, the following recommendation for evaluation the cyclic behavior of silty soils is as follows. Evaluation of cyclic behavior of silty soils in the pacific northwest should be based on CPT obtained SBT index, Ic, as well as laboratory determined PI. For soils with PI of 7 or less and Ic of 2.6 or less, Idriss and Boulanger (2014) deterministic relationship for fines content of 70 provides a reasonable estimate of CRR. However the FC must be determined either with CPT-FC correlations or P200 to be greater than 50 . Soils with PI greater than 7 and Ic greater than 2.6, Idriss and Boulanger (2008) with $\mathrm{N}_{\mathrm{kt}}=15$ provides a reasonable estimate of CRR. The transitional samples that fall within these two 
relationships can be estimated using the Idriss and Boulanger (2014) FC=70 line for a conservative estimate of cyclic soil behavior.

Other areas of future work outside of the analyses in this research may include the further analysis of OCR effect on CRR, CPT porewater pressure measurements, SPT, and shear wave velocity. Also, the behavior of the soil during cyclic loading can be analyzed and compared with the $\mathrm{q}_{\mathrm{c}}-\mathrm{CRR}$ relationships presented herein to further explore any liquefaction or cyclic softening effects. These additional parameters may reveal trends within the data presented herein but outside the scope of this dissertation. 


\section{References}

Ahmadi, M M, \& Robertson, P K. (2005). Thin-layer effects on the CPT qc measurement. Canadian Geotechnical Journal, 42(5), 1302-1317.

Andrus, R., \& Stokoe, K. (2000). Liquefaction resistance of soils from shear-wave velocity. Journal of Geotechnical and Geoenvironmental Engineering, 126(11), 1015-1026.

Boulanger, R.W. and DeJong, J.T. (2018)“Inverse filtering procedure to correct cone penetration data for thin-layer and transition effects", CPT '18 Conference, June 21-22, 2018, 19 pp.

Briaud, Jean-Louis. (2013). Shear Strength Properties. In Geotechnical Engineering (pp. 443-471). Hoboken, NJ, USA: John Wiley \& Sons.

Boulanger, Ross W, \& Idriss, I. M. (2006). Liquefaction Susceptibility Criteria for Silts and Clays. Journal of Geotechnical and Geoenvironmental Engineering, 132(11), 1413-1426.

Boulanger, R. W., and Idriss, I. M. (2014). “CPT and SPT based liquefaction triggering procedures." Report No. UCD/CGM-14/01, Center for Geotechnical Modeling, Department of Civil and Environmental Engineering, University of California, Davis, CA, $134 \mathrm{pp}$.

Bray, Jonathan D, \& Sancio, Rodolfo B. (2006). Assessment of the Liquefaction Susceptibility of Fine-Grained Soils. Journal of Geotechnical and Geoenvironmental Engineering, 132(9), 1165-1177. 
Idriss, I., Boulanger, Ross W, \& Earthquake Engineering Research Institute. (2008). Soil liquefaction during earthquakes (Publication (Earthquake Engineering Research Institute) ; MNO-12). Oakland, Calif.: Earthquake Engineering Research Institute.

Karim, Mohammad Emdadul, \& Alam, Md. Jahangir. (2014). Effect of non-plastic silt content on the liquefaction behavior of sand-silt mixture. Soil Dynamics and Earthquake Engineering, 65, 142-150.

Price, A. B., Boulanger, R. W., DeJong, J. T., Parra Bastidas, A. M., and Moug, D. (2015). "Cyclic strengths and simulated CPT penetration resistances in intermediate soils." 6th International Conference on Earthquake Geotechnical Engineering, November 1-4, Christchurch, New Zealand.

Robertson, P. (1990). Soil classification using the cone penetration test. Canadian Geotechnical Journal, 27(1), 151-158.

Robertson, P.K. and Wride, C. (1998) Evaluating Cyclic Liquefaction Potential Using the Cone Penetration Test. Canadian Geotechnical Journal, 35, 442-459.

Robertson, P. K. (2009). Interpretation of cone penetration tests - a unified approach. Canadian Geotechnical Journal, 46(11), 1337-1355.

Robertson, P.K. (2010a) Soil behavior type from the CPT: an update. $2^{\text {nd }}$ International Symposium on Cone Penetration Testing, CPT'10, Huntington Beach, CA, USA. 
National Academies of Sciences, Engineering, and Medicine. 2016. State of the Art and Practice in the Assessment of Earthquake-Induced Soil Liquefaction and Its Consequences. Washington, DC: The National Academies Press. doi: 10.17226/23474

Shuttle, Dawn A, \& Cunning, John. (2007). Liquefaction potential of silts from CPTu. Canadian Geotechnical Journal, 44(1), 1-19. 
Appendix A Project Site Data Source Summary:

The material in this appendix is included as a separate file. File is a .pdf (599

$K B)$; the second page of the file is created on a $11.00 \times 17.00$ in. page. 


\section{Appendix B: Summary In-Situ Parameters}

The material in this appendix is included as a separate file. File is a .pdf (444 KB); the second and third pages of the file are created on $11.00 \times 17.00$ in. pages. 